\title{
Characterisation of two-stage ignition in diesel engine-relevant thermochemical conditions using direct numerical simulation
}

\author{
Alex Krisman ${ }^{\mathrm{a}, \mathrm{b}, *}$, Evatt R. Hawkes ${ }^{\mathrm{a}, \mathrm{c}}$, Mohsen Talei $^{\mathrm{d}}$, Ankit Bhagatwala ${ }^{\mathrm{b}}$, Jacqueline H. Chen ${ }^{\mathrm{b}}$ \\ ${ }^{a}$ School of Mechanical and Manufacturing Engineering, The University of New South Wales, Sydney, NSW 2052, \\ Australia \\ ${ }^{b}$ Combustion Research Facility, Sandia National Laboratories, Livermore, CA 96551-0969, USA \\ ${ }^{c}$ School of Photovoltaic and Renewable Energy Engineering, The University of New South Wales, Sydney, NSW \\ 2052, Australia \\ ${ }^{d}$ Department of fluid mechanics, The University of Melbourne, Melbourne, VIC 3052, Australia
}

\begin{abstract}
With the goal of providing a more detailed fundamental understanding of ignition processes in diesel engines, this study reports analysis of a direct numerical simulation (DNS) database. In the DNS, a pseudo turbulent mixing layer of dimethyl ether (DME) at $400 \mathrm{~K}$ and air at $900 \mathrm{~K}$ is simulated at a pressure of 40 atmospheres. At these conditions, DME exhibits a two-stage ignition and resides within the negative temperature coefficient (NTC) regime of ignition delay times, similar to diesel fuel. The analysis reveals a complex ignition process with several novel features. Autoignition occurs as a distributed, two-stage event. The high-temperature stage of ignition establishes edge flames that have a hybrid premixed/autoignition flame structure similar to that previously observed for lifted laminar flames at similar thermochemical conditions. A combustion mode analysis based on key radical species illustrates the multi-stage and multi-mode nature of the ignition process and highlights the substantial modelling challenge presented by diesel combustion.

Keywords: diesel-relevant, ignition kernel, autoignition, edge flame, cool flame, negative temperature coefficient, tetrabrachial, direct numerical simulation, mixing layer
\end{abstract}

\section{Introduction}

Future diesel engines will be required to attain cost-effective reductions in pollutant emissions while improving fuel economy. These improvements will arguably be easier to attain with improved fundamental understanding of diesel engine combustion, which can be built into practically useful

*Mob.:(925) 294.3896

Email address: ankrism@sandia.gov (Alex Krisman) 
computational models to be used in engine design. With the goal of providing this understanding, experimental and numerical studies have been carried out.

Experiments conducted in optically accessible diesel engines and chambers have visualised ignition and flame stabilisation using high speed cameras and laser diagnostics [1-3]. The results suggest that diesel combustion is a multi-stage and multi-mode process. Observations of natural chemiluminescence, soot luminosity, and planar laser-induced fluorescence (PLIF) have been able to infer the existence of low- and high-temperature autoignition, premixed combustion, and nonpremixed combustion (diffusion flames). Such visual observations form the basis for conceptual models of diesel combustion that have been proposed for conventional [1-3] and low-temperature [3] diesel engines .

In conventional diesel engines, the fuel is injected near the end of the compression stroke and the air charge is not substantially diluted with exhaust gasses. This results in highly stratified combustion with locally very rich mixtures (having high values of mixture fraction, $\xi$ ) and high temperatures. Following ignition, a quasi-stable lifted flame develops. The lifted flame is thought to exhibit a nonpremixed (diffusion flame) region, centered on the stoichiometric mixture fraction $\left(\xi_{S T}\right)$, and a rich premixed region within the fuel jet, and, in typical ambient conditions, a region of first stage ignition (or a "cool flame") due to low-temperature chemistry (LTC) that exists ahead of and/or inside the high-temperature chemistry (HTC) region [2-4]. The lifted flame is anchored at the most upstream location of nonpremixed combustion (the lift-off length, LOL). High levels of NOx formation are thought to occur in the hot, near-stoichiometric diffusion flame, while high levels of soot formation are thought to occur in the hot and rich inner region. Strategies to reduce pollutant formation are therefore focused on lowering peak temperatures and increasing the degree of premixing (entrainment) prior to combustion, which is closely related to parameters such as the homogeneous ignition delay time, $\tau$, and the LOL. The reduction of pollutants therefore requires an understanding of the physical processes that govern ignition and flame stabilisation.

Autoignition in stratified mixtures at atmospheric conditions has been extensively studied (e.g., see the review by Mastorakos [5]). A chief conclusion is that autoignition is sensitive to both $\xi$ and the scalar dissipation rate, $\chi$, such that autoignition first occurs at locations where the local mixture is near the homogeneous most reactive $\xi$ value, $\xi_{M R}[6]$, and the $\chi$ is low [6-13]. Experiments of 
autoigniting, turbulent, stratified flows at atmospheric pressure have been performed by Markides et al. [14-16]. In those studies, the configuration of an axis-symmetric fuel jet, co-flowing with hot air was considered. A statistically stationary state was achieved, whereby the rapid succession of independent autoignition events (kernels) formed at "random spots" (in physical space) and were convected downstream without establishing a connected flame surface. A direct numerical simulation (DNS) targeting similar conditions was also conducted [17], which confirmed that the kernels formed where the local mixture was near $\xi_{M R}$ and experiencing low $\chi$ rates. Another recent experiment of a turbulent, autoigniting jet simultaneously measured $\xi$ and temperature [18]. The results provided further experimental evidence that ignition kernels form preferably at $\xi_{M R}$ locations where the $\chi$ is low. For diesel engine-relevant conditions, temporally and spatially resolved experimental observations of autoignition do not currently exist.

The stabilisation mode of turbulent lifted flames is an open topic of research. At atmospheric pressure, a range of stabilisation mechanisms have been proposed based on theories of, e.g., premixed flame propagation [19], nonpremixed flamelet extinction [20], edge flame propagation [21-23], large scale turbulence [24], and autoignition [25-29], without a clear consensus having yet been arrived at $[30,31]$. For engine-relevant conditions, the stabilisation method is even less clear due to difficulties in taking well-resolved measurements. The available conceptual models [1-3] do not explicitly state which stabilisation mode or modes are responsible for diesel flame stabilisation and there remains ambiguity as to the flame structure in the vicinity of the flame base. For example, diagrams of quasi-stable diesel flames $[2,3]$ are consistent with both flame stabilisation by two-stage autoignition and edge flame propagation into a region of first-stage autoignition (or a cool flame). A review study of stabilisation modes in diesel jets by Venugopal and Abraham [32] concluded that multiple stabilisation modes (with contradictory assumptions) could each partially explain the stabilisation behaviour observed in experiments. This indicates that the underlying physical behaviour of diesel combustion is not well understood.

A major impediment to modelling diesel combustion is the limited fidelity of experimental observation. Existing techniques are limited to qualitative descriptions of the flame structure and global observables such as LOL and $\tau$, but additional information is required when designing and evaluating combustion models, particularly when comparing incongruous models. Additional well- 
resolved observations at diesel engine-relevant conditions are therefore required.

An alternative approach is to conduct DNS which serve as "numerical experiments" that fully resolve all spatial and temporal scales. The main limitation to DNS is the extreme computational cost, which is highly sensitive to the range of scales in the target simulation and the complexity of the underlying physics. Diesel combustion exhibits: multi-phase behaviour, thousands of chemical reactions, and an extremely large range of scales, which makes an engine-level application of DNS infeasible. However, by making appropriate simplifying assumptions, idealised DNS may be conducted that complement physical experiments and provide additional insight into diesel combustion. The growth of high performance computing resources has enabled several DNS investigations of diesel engine-relevant combustion at idealised conditions [33-41], the main findings of which are reviewed here.

Sreedhara and Lakshmisha [33] conducted a three-dimensional (3D) DNS study of $n$-heptane ignition in decaying isotropic turbulence. Ensemble-averaged results showed that high-temperature ignition occurred over a range of rich $\xi$ values (approximately corresponding to $\xi_{M R}$ ) experiencing low $\chi$. That result was consistent with prior ignition studies conducted at non-engine-relevant conditions $[5]$.

DNS studies of the ignition of laminar [34] and turbulent [35, 36] two-dimensional (2D) mixing layers were conducted by Mukhopadhyay and Abraham. The effect of mixing layer thickness $(\sigma)$ on $\tau$ was studied in the laminar cases and it was observed that at low values of $\sigma$ (highly stratified, corresponding to high $\chi$ values), $\sigma$ and $\tau$ were negatively correlated. The turbulent ignition cases observed that both the first- and second-stages of autoignition were delayed by high values of $\chi[36]$ and the second-stage of ignition influenced the $\chi$ field due to enhanced diffusion at the leading edge of the ignition (which promoted $\chi$ ) and reduced compositional gradients behind the ignition front due to heat release (which lowered $\chi$ ) [35].

A DNS study of the autoignition of a sparse spray of $n$-heptane at a pressure of 24 bar was performed by Borghesi et al. [37]. The visualisation of the temperature field showed that the autoignition occurred in a "spotty" pattern. Statistics conditioned upon $\xi$ and $\chi$ also revealed a two-staged ignition where the second-stage of ignition was negatively correlated with $\chi$. The high-temperature ignition was also observed to occur first in mixtures slightly richer than $\xi_{M R}$. 
Several DNS studies targeting diesel condition and using dimethyl ether (DME) fuel have recently been performed [38-41]. DME is an attractive diesel surrogate fuel as it exhibits a similar two-stage ignition and negative temperature coefficient (NTC) regime of ignition delay times also observed for diesel fuels [42]. DME is also a low-sooting, potentially renewable fuel with a high cetane number, and a potential alternative to diesel fuel in real engines [43]. DME can also be modelled with compact chemical mechanisms [44], which is attractive for DNS.

A study of laminar lifted flame stabilisation at diesel engine-relevant conditions using a 30 species reduced chemical mechanism for DME was conducted by the present authors [38]. That study considered the parametric variation of oxidiser temperature over a range which spanned the NTC regime. The study identified that hybrid edge flame/autoignition structures and stabilisation modes may exist at diesel-relevant thermochemical conditions and that a gradual transition from primarily edge flame propagation to primarily autoignition stabilisation was observed with increasing oxidiser temperature. For the case of $900 \mathrm{~K}$ oxidiser temperature, a main tribrachial (triple) flame was observed with an additional, fourth branch upstream of the stabilisation location due to LTC. The four-branched edge flame was termed a tetrabrachial flame and it broadly resembled the flame structure presented in conceptual models of conventional diesel combustion. This result suggested that a combination of both autoignition and edge flame propagation could contribute to diesel flame stabilisation.

Subsequent DNS at similar conditions by Deng et al. [39, 40] also observed the hybrid flame structures and a stabilisation mode transition from edge flame propagation to autoignition with increasing oxidiser temperature for a fixed inlet velocity [39] or increasing inlet velocity for a fixed oxidiser temperature [40]. Chemical explosive mode analysis (CEMA) was used which provided further evidence in support of the findings from the previous study [38].

A 2D turbulent mixing layer DNS of ignition [41] was recently conducted by the present authors at identical thermochemical conditions to the lifted laminar flame case with an oxidiser temperature of $900 \mathrm{~K}$ [38]. The focus of the mixing layer study was on the behaviour of LTC and its interactions with the high-temperature ignition. It was found that the LTC develops initially as a first-stage autoignition in lean mixtures (low $\xi$ values), approximately equal to the first stage, most reactive mixture fraction $\left(\xi_{M R, 1}\right)$ conditioned upon low $\chi$ values. The LTC then transitioned to a diffusively 
supported "cool flame" which propagated into richer $\xi$. The cool flame propagation behaved as a low-temperature deflagration, not an ignition front due to gradients in the first stage ignition delay time $\left(\tau_{1}\right)$. The cool flame shortened the onset of both LTC and HTC reactions preferentially at richer mixtures, causing high-temperature ignition kernels to develop in mixtures much richer than the most reactive mixture fraction value $\left(\xi_{M R}\right)$ as calculated in a homogeneous reactor. The results also identified additional features of interest that were not analysed in Ref. [41], such as a transition from discrete autoignition "kernels" to edge flame formation and propagation. The presence of LTC and HTC reactions, and autoignition and edge flame propagation, produced a complex overall ignition.

A major finding from the recent DNS studies using detailed DME chemistry [38-41] is that diesel-relevant combustion can involve a large number of combustion modes. For LTC, autoignition and deflagrations (cool flames) are observed; for HTC, autoignition, rich premixed, lean premixed, and nonpremixed (diffusion flames) are observed. This potentially leads to very complex ignition and stabilisation processes. As preliminarily identified [41], all of these combustion modes may occur in a single ignition case, and these modes may overlap in time. The details of this process may be important for understanding and modelling diesel combustion, and it therefore merits further consideration.

The main objective of this study is to expand upon the analysis presented in Ref. [41], which was primarily concerned with the LTC behaviour, using the same dataset (To reviewers: Ref. [41] is included in the supplementary materials to this submission). In the present work, the overall ignition process is considered, including the HTC features of ignition kernel and edge flame evolution. The following specific questions will be addressed:

- What is the qualitative behaviour of the LTC and HTC modes during ignition?

- How do the statistics of LTC and HTC evolve in $\xi$ space and what is the effect of conditional fluctuations of $\chi$ ?

- How do the autoignition kernels transition to propagating edge flames?

- Are the edge flames similar to those observed in lifted, laminar studies [38-40]? 
- How does the edge flame propagation speed respond to fluctuations in $\chi$ and the upstream chemical state?

- What combustion modes are present and how do they evolve in time?

The results are presented in six parts. Firstly, the overall ignition process is characterised in terms of the qualitative and statistical behaviour in sections 3.1 and 3.2, respectively, expanding upon the cursory overview provided in Ref. [41]. For orientation, a brief description of the LTC and its effect on the high-temperature ignition follows in section 3.3, which restates the chief findings presented in Ref. [41]. The growth of the autoignition kernels and the formation of edge flames is detailed in section 3.4. In section 3.5, the propagation speeds of edge flames are measured in terms of their displacement speeds, and correlations are presented with respect to local mixing rates and chemical progress ahead of the edge flames. Finally, in section 3.6, a method of combustion mode analysis based upon key species mass fraction thresholds is proposed, which discriminates between various modes of combustion. The combustion mode analysis unifies many observations from the prior results and comparisons are made with conceptual models of diesel combustion.

\section{Configuration}

The numerical method and the configuration of the computational domain are identical to that presented in Ref. [41], so only a brief overview is provided here for orientation.

The objective in setting up the DNS was to represent the ignition of a fuel-stratified ignition in diesel-relevant thermochemical conditions. As already mentioned, DME was selected for the fuel due to the availability of a short chemical mechanism and its reproduction of the essential features

of diesel autoignition, namely two-stage ignition and negative-temperature coefficient behaviour. At the chosen thermochemical ambient conditions of a pressure of 40 bar and oxidiser temperature of 900K, very thin flames are observed, necessitating grid sizes of 1 micron. As a result, 3D runs were not feasible with non-laminar Reynolds numbers, and therefore the configuration of the ignition of a 2D mixing layer was adopted.

The mixing layer is initially laminar in composition and subject to a field of decaying isotropic pseudo-turbulence. 
The 2D domain was $3.6 \mathrm{~mm}$ by $3.6 \mathrm{~mm}$ in size, consisting of a periodic direction, $x$, and a non-periodic direction, $y$. A mixing layer of thickness $\sigma=25 \mu \mathrm{m}$ was imposed at the plane $y=0$. The initial $\xi$ profile was described by

$$
\xi(y)=\frac{1}{2}\left(1+\tanh \left(\frac{y-\frac{1}{2}\left(y_{M A X}-y_{M I N}\right)}{\sigma}\right)\right)
$$

and the temperature profile was determined by adiabatic mixing between the fuel and oxidiser streams. The oxidiser was air $\left(21 \% \mathrm{O}_{2}\right.$ and $\left.79 \% \mathrm{~N}_{2}\right)$ at $900 \mathrm{~K}$ and the fuel was DME $(70 \% \mathrm{DME}$ and $30 \% \mathrm{~N}_{2}$ ) at $400 \mathrm{~K}$.

An initial spectrum of isotropic turbulence was superimposed on the stationary mean flow field as the initial condition. The turbulence had a Damkhöler number, Da, of 0.4, defined as $\mathrm{Da}=\tau_{E} / \tau_{\left(\xi=\xi_{M R}\right)}$, where $\tau_{E}$ is the characteristic eddy time defined as $\tau_{E}=L_{t} / u^{\prime}, L_{t}$ is the integral length scale equal to $0.1 \mathrm{~mm}, u^{\prime}$ is the root mean squared (RMS) turbulent velocity fluctuations equal to $0.486 \mathrm{~ms}^{-1}$, and $\tau_{\left(\xi=\xi_{M R}\right)}$ is the ignition delay time of the most reactive $\xi$, as measured in a homogeneous reactor. This Da was selected to match the approximate Da at the location of ignition under representative conditions, as estimated from Reynolds-averaged Navier-Stokes (RANS) computations of a diesel spray flame [4]. The turbulent Reynolds number, $\operatorname{Re}_{t}=u^{\prime} L_{t} /$ $\nu$, was equal to 23.4. This value was maximised within the constraints of the domain size and the target Da. The turbulent fluctuations were tapered to zero for the regions near the $y$ boundaries, for numerical stability. Non-dimensional parameters are defined as follows: $x^{*}=x / L_{t}, y^{*}=y / L_{t}$, and $t^{*}=t / \tau_{\left(\xi=\xi_{M R}\right)}$.

The simulation was performed using S3D [45-52]. S3D solves the compressible Navier Stokes, conservation of energy, mass, and species mass fraction equations on a structured mesh. S3D uses eighth-order central differencing scheme for spatial derivatives and a fourth-order explicit RungeKutta method for time advancement. The solution was filtered every ten time steps using a tenthorder explicit filter. A Navier Stokes characteristic boundary condition (NSCBC) method was used for the non-reflecting outflow at the $y$ boundaries.

The simulation was performed on a uniform mesh in the $x$ direction and stretched in the $y$ direction, with a fine-mesh region, having a width of $1.8 \mathrm{~mm}$, centred at $y=0$. The fine-mesh 
region had a grid spacing of $1 \mu \mathrm{m}$ in both directions and the solution was advanced with a time step of 1 ns. The grid spacings were selected in order to place a minimum of 12 grid points across the smallest flame structures. The computational cost of the simulation was approximately 200,000 CPU hours on Intel Ivy Bridge processors.

A 30 species reduced DME chemical mechanism [44] derived from a 50 species detailed mechanism was used [42]. The chemical mechanism was identical to that used in a previous study of lifted laminar flames [38].

\section{Results}

\subsection{Qualitative description}

A qualitative description of the overall ignition process is now provided. To this end, Figs. 1 and 2 show instantaneous images for a fixed window of the domain $(1.2 \mathrm{~mm} \times 1.2 \mathrm{~mm}$ in size $)$. The domain sample shown is representative of the entire domain. As already mentioned, the DNS was introduced in Ref. [41], where an overview was presented in terms of a time-series of heat release rates. In this section, the description is expanded to several additional variables, in order to gain a more complete overview of the ignition event. The chemical species shown in Fig. 2 are selected in order to highlight distinct combustion modes which are analysed in section 3.6. These species are: methoxymethyl peroxy radical $\mathrm{CH}_{3} \mathrm{OCH}_{2} \mathrm{O}_{2}$, an excellent marker for LTC reactions [38]; water vapour $\mathrm{H}_{2} \mathrm{O}$, a product species which serves as a progress variable; and hydroxyl radical OH, which isolates regions of HTC near the $\xi_{S T}$ surface.

Concerning the results shown in Figs. 1 and 2 , at $t^{*}=0.4$, the heat release rate $(\mathrm{HRR})$ is initiated within lean mixtures and has a low intensity. The HRR is collocated with low $\chi$ regions that have significant $\mathrm{Y}_{\mathrm{CH}_{3} \mathrm{OCH}_{2} \mathrm{O}_{2}}$ levels, while $\mathrm{Y}_{\mathrm{H}_{2} \mathrm{O}}$ and $\mathrm{Y}_{\mathrm{OH}}$ levels are insignificant compared to their equilibrium values, showing that LTC is occurring at this time. As time progresses, the region of peak HRR progresses into increasingly rich $\xi$ (crossing $\xi_{S T}$ by $\mathrm{t}^{*}=0.8$ ) where $\chi$ values are higher. Until t* $=1.2$, HRR and $\mathrm{Y}_{\mathrm{CH}_{3} \mathrm{OCH}_{2} \mathrm{O}_{2}}$ remain collocated. During this time, $\mathrm{Y}_{\mathrm{H}_{2} \mathrm{O}}$ levels are gradually increasing and moderate temperature rise is observed while $\mathrm{Y}_{\mathrm{OH}}$ levels are insignificant.

By $\mathrm{t}^{*}=1.6$, regions of intense HRR have formed, centred on $\xi_{S T}$. These features have a shape which resembles a tribrachial HTC edge flame propagating into a weaker LTC branch ahead of the 
edge flame triple point. The regions bounded by the intense HRR have very high levels of $\mathrm{Y}_{\mathrm{H}_{2} \mathrm{O}}$, high $\mathrm{T}$, and high levels of $\mathrm{Y}_{\mathrm{OH}}$ where $\xi \approx \xi_{S T}$, showing that $\mathrm{HTC}$ is occurring in these regions.

These observations can be explained by a two-stage autoignition process which leads to multiple edge flame deflagrations. The presence of $\mathrm{Y}_{\mathrm{CH}_{3} \mathrm{OCH}_{2} \mathrm{O}_{2}}$ identifies the initial HRR as a LTC feature. Starting from isolated regions at $\mathrm{t}^{*}=0.4$, the LTC forms a wrinkled surface that moves up the mixture fraction gradient (from lean to rich). Between $t^{*}=1.2$ and $t^{*}=1.6$ (not shown in Fig. 1), the second HTC stage of autoignition is initiated from discrete locations (kernels) which rapidly expand and engulf the $\xi_{S T}$ surface, establishing edge flames.

The HTC autoignition kernels evolve very rapidly after their initial appearance. Figure 3 shows the HRR field for the same window as in Fig. 1, but evaluated at a smaller time interval of $t^{*}=$ 0.04 between $\mathrm{t}^{*}=1.20$ and $\mathrm{t}^{*}=1.40$, during which time, two autoignition kernels are formed. At $\mathrm{t}^{*}=1.20$, no autoignition kernels are present. The HRR is of low intensity, and exists as a wrinkled interface centred on $\xi \gg \xi_{S T}$. At $t^{*}=1.24$, a localised region of intense HRR (a kernel) has developed in a region of rich $\xi$. Between $\mathrm{t}^{*}=1.24$ and 1.32 , the first kernel expands, rapidly engulfing the $\xi_{S T}$ surface. A second ignition kernel has formed by $\mathrm{t}^{*}=1.32$, located farther in physical space (and $\xi$-space, not shown here) from the $\xi_{S T}$ surface. By $\mathrm{t}^{*}=1.40$, the first kernel appears to have established two edge flames propagating in opposite directions and along the $\xi_{S T}$ surface. A characteristic tribrachial (triple) flame is observed, moving into a partially reacted mixture. The second ignition kernel expands more slowly than the first one. The rich premixed branches of the edge flame move quickly into richer $\xi$, merging with and consuming the existing region of HRR that is associated with the LTC. The two kernels described in Fig. 3 are representative of the 18 discrete kernels observed over the course of the simulation. Most kernels have qualitatively similar behaviour, forming in very rich $\xi$. Some kernels merge with earlier-formed kernels, or are overtaken by propagating edge flames before they can reach $\xi_{S T}$ and establish additional edge flames.

The transition from autoignition kernels to edge flame propagation is consistent with previous DNS studies by Domingo and Vervisch [53] using single-step chemistry and Echekki and Chen [54] and Kerkemeier et al. [17] with detailed hydrogen chemistry. The thermochemical conditions in those cases precluded the two-stage autoignition and the hybrid edge flame/autoignition structures observed here. 

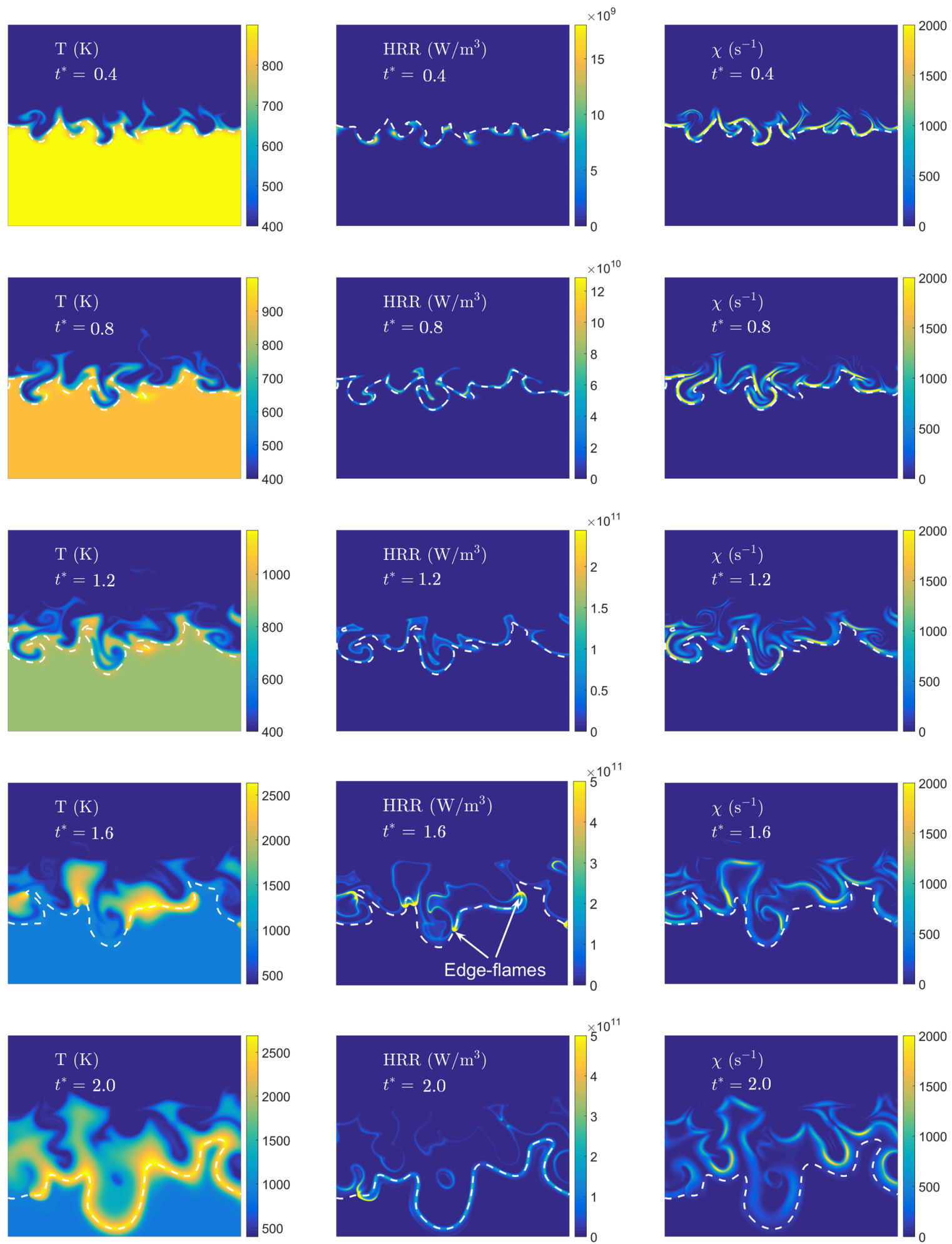

Figure 1: Instantaneous views of key variables for a sequence of times. Each row represents an instant in time in increments of $t^{*}=0.4$. The left column is $\mathrm{T}(\mathrm{K})$, the middle column is $\mathrm{HRR}\left(\mathrm{W} / \mathrm{m}^{3}\right)$, and the right column is $\chi(1 / \mathrm{s})$. Examples of edge flames are highlighted in the fourth HRR subfigure. The dashed white line represents the $\xi_{S T}$ surface. The top (above the $\xi_{S T}$ surface) of each image corresponds to fuel rich mixtures and the bottom corresponds to fuel lean mixtures. Note that the legends are not constant for the left and middle column. 

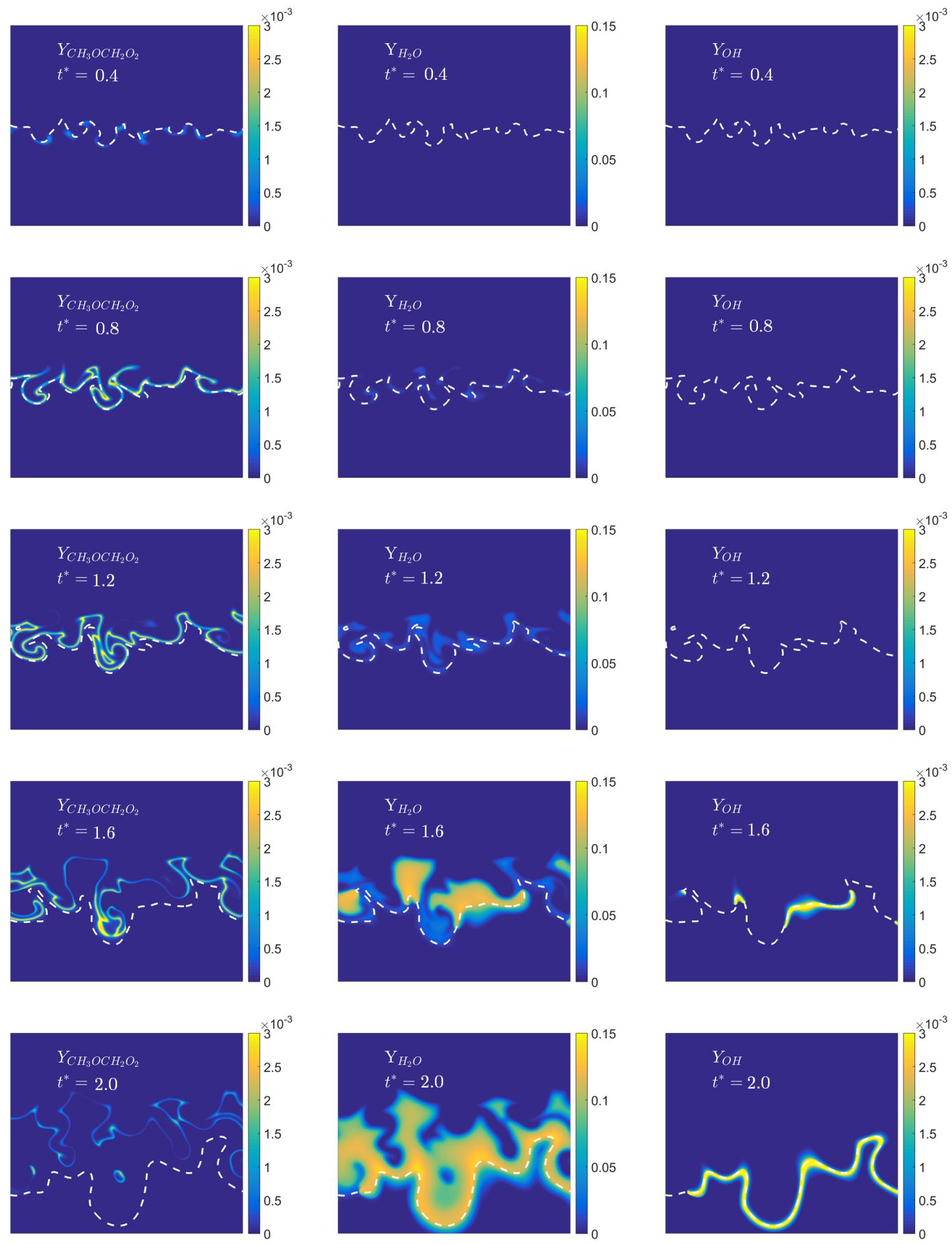

Figure 2: Instantaneous views of fixed window in time. Each row represents an instant in time in increments of $\mathrm{t}^{*}=$ 0.4. The left column is $\mathrm{Y}_{\mathrm{CH}_{3} \mathrm{OCH}_{2} \mathrm{O}_{2}}$, the middle column is $\mathrm{Y}_{\mathrm{H}_{2} \mathrm{O}}$, and the right column is $\mathrm{Y}_{\mathrm{OH}}$. The dashed white line represents the $\xi_{S T}$ surface. The top (above the $\xi_{S T}$ surface) of each image corresponds to fuel rich mixtures and the bottom corresponds to fuel lean mixtures 

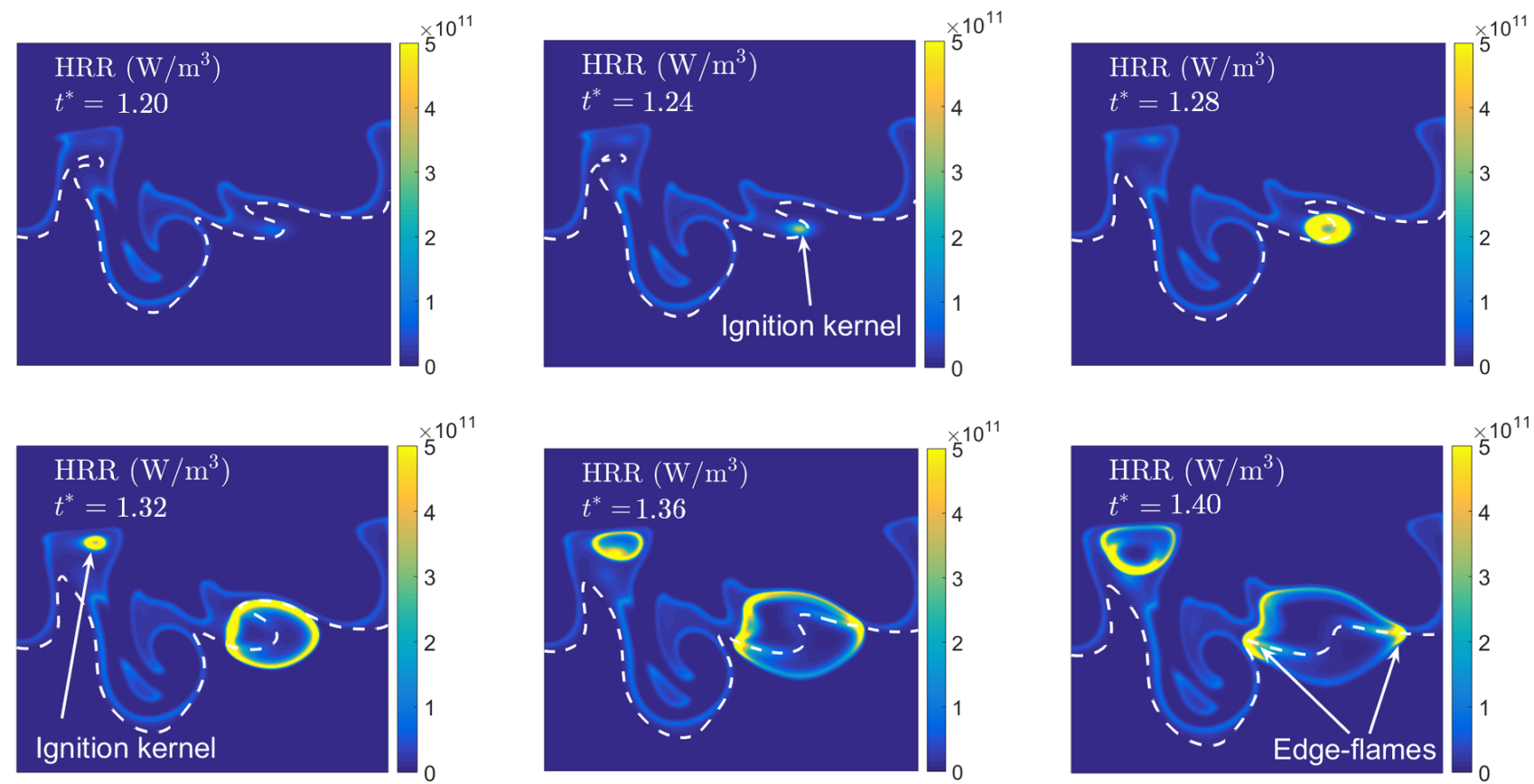

Figure 3: Fields of HRR for a sequence of time instants. The window extent is 1.2 to $2.4 \mathrm{~mm}$ in the x-direction and -0.6 to $0.6 \mathrm{~mm}$ in the y-direction. The colour shading shows the HRR and the dashed white line shows $\xi_{S T}$. The top (above the $\xi_{S T}$ surface) of each image corresponds to fuel rich mixtures and the bottom corresponds to fuel lean mixtures.

\subsection{Conditional statistics}

Statistics were gathered over the entire domain for T, HRR, and $\chi$ and are presented in Fig. 4. The scatter data represents randomly selected sample points in the domain (one fifth of the domains points are shown in the figure), the solid line represents the mean quantity conditioned on $\xi$ and the error bars bracket the mean curve by \pm 1 standard deviation. The statistics are evaluated at intervals of $\mathrm{t}^{*}=0.4$.

The micro-mixing field measured by $\chi$ has a peak value near $\xi=0.4$ at $\mathrm{t}^{*}=0.4$. Over time, the mixing rates generally relax, but $\chi$ is highly intermittent. At $\mathrm{t}^{*}=1.6$, outlier samples with very high $\chi$ are observed even as the mean $\chi$ continues to relax. In Section 3.4 this will be shown to be associated with rich premixed flames.

The HRR has a small peak at about $\xi=0.05$ for $\mathrm{t}^{*}=0.4$. After this time, the conditional mean HRR rapidly increases in peak value. By $\mathrm{t}^{*}=0.8$, the peak value has moved into rich $\xi$, and the profile occupies a broad region in $\xi$ space. By $\mathrm{t}^{*}=1.2$, the region of elevated HRR has broadened and the peak has moved into richer $\xi$, but the peak value is essentially unchanged. However, the scatter data shows small regions of the domain, which are extreme outliers, that are experiencing 
very high HRR compared to the conditional mean. Visual inspection reveals that these outlying points correspond to locations which will soon form ignition kernels (not shown here). By $\mathrm{t}^{*}=$ 1.6, the conditional mean profile of HRR has substantially changed. Two peaks (modes) are now observed. The first mode is centred at $\xi_{S T}$ and the second mode is centred at about $\xi=0.4$. The level of HRR fluctuation has also substantially increased. At $t^{*}=2.0$, the two modes are more distinct, the amount of scatter is reduced and the conditional standard deviation is much lower. It will be shown later than the HRR peak near $\xi_{S T}$ is associated with HTC and the second lower peak in rich mixtures is due to LTC.

The conditionally averaged profiles for temperature are consistent with those of the HRR. From $\mathrm{t}^{*}=0.4$ to $\mathrm{t}^{*}=1.2$, two branches are observed: a low-temperature branch representing the effects of the LTC, and the frozen mixing branch representing the non-reacting solution, which is not easily distinguishable in Fig. 4 from the low-temperature branch due to the proximity of the two branches. The development of the low-temperature branch closely follows the HRR result from $\mathrm{t}^{*}=0.4$ to 1.2. During this phase the LTC is spreading to non-reacting mixtures, gradually consuming the frozen mixing line branch. At $\mathrm{t}^{*}=1.2$, the local extrema from the HRR scatter plot correspond to the emerging peaks in the scatter in temperature. At $\mathrm{t}^{*}=1.6$, an additional high-temperature branch is observed. By $\mathrm{t}^{*}=2.0$, the high-temperature branch has strengthened compared to the low-temperature branch.

The results at $\mathrm{t}^{*}=2.0$ show an instant in the transition between LTC and HTC dominated combustion. It is interesting to note that the first and second conditional moments can not represent the bi-modalilty of the conditional PDF of $\mathrm{T}$ at that time. This has implications for model selection for cases where multiple branches (modes) exist, which will be discussed shortly. Furthermore, the results show that there is a significant time over which both LTC and HTC effects are important to consider. From about $\mathrm{t}^{*}=1.24$ to $\mathrm{t}^{*}=2.2$, an overlap in HTC and LTC is observed.

Statistics were also gathered for key species $\mathrm{Y}_{\mathrm{CH}_{3} \mathrm{OCH}_{2} \mathrm{O}_{2}}, \mathrm{Y}_{\mathrm{H}_{2} \mathrm{O}}$, and $\mathrm{Y}_{\mathrm{OH}}$; these are presented in Fig. 5.

The $\mathrm{Y}_{\mathrm{CH}_{3} \mathrm{OCH}_{2} \mathrm{O}_{2}}$ distribution has a peak at $\mathrm{t}^{*}=0.4$ and centered at lean $\xi$, which closely matches the peak in HRR observed in Fig. 4. Since $\mathrm{Y}_{\mathrm{CH}_{3} \mathrm{OCH}_{2} \mathrm{O}_{2}}$ is produced only in the presence of LTC, this confirms that the initial temperature rise and heat release observed is indeed due to LTC. 
From $\mathrm{t}^{*}=0.4$ to 1.2 , the behaviour of $\mathrm{Y}_{\mathrm{CH}_{3} \mathrm{OCH}_{2} \mathrm{O}_{2}}$ closely follows that of the HRR. At the same time, the values of $\mathrm{Y}_{\mathrm{H}_{2} \mathrm{O}}$ and $\mathrm{Y}_{\mathrm{OH}}$ are low (compared to their equilibrium values observed at later times). This observation holds true generally, i.e., species confined to LTC pathways approximately follow the HRR distribution up to $\mathrm{t}^{*}=1.2$, and species associated with HTC pathways are not present in significant quantities. Based on these observations, the HRR prior to the formation of autoignition kernels is attributed to LTC.

From $\mathrm{t}^{*}=1.2$ to 2.0 , rapid development of the $\mathrm{HTC}$ is observed. At $\mathrm{t}^{*}=1.2$, peaks in $\mathrm{Y}_{\mathrm{H}_{2} \mathrm{O}}$ are forming at $\xi$ values corresponding to those observed in the HRR and $\mathrm{T}$ results. At $\mathrm{t}^{*}=1.6$, two distinct branches are observed for the $\mathrm{Y}_{\mathrm{H}_{2} \mathrm{O}}$ profile. These two branches correspond to the high and low-temperature branches from Fig. 4. Again, the first and second conditional moments do not reflect the bi-modality of the conditional PDFs of the composition during ignition. By $\mathrm{t}^{*}=$ 2.0, the statistics are converging to the high-temperature branch. At very rich $\xi$, the $\mathrm{Y}_{\mathrm{CH}_{3} \mathrm{OCH}_{2} \mathrm{O}_{2}}$ is still observed, but at lower $\xi$ this LTC species has been consumed by the HTC reactions.

The correspondence between $\mathrm{T}$ and $\mathrm{Y}_{\mathrm{H}_{2} \mathrm{O}}$ suggests that $\mathrm{H}_{2} \mathrm{O}$ is a chemical species which closely corresponds to the burning state of the mixture, i.e., regions with no $\mathrm{Y}_{\mathrm{H}_{2} \mathrm{O}}$ are unburnt, regions of intermediate value are partially burnt due to LTC, and regions of high value reside on the equilibrium line and are fully burnt due to HTC. This observation has been confirmed via visual inspection, e.g., see Fig. 4. The result is also consistent with simulations of NTC affected ignition [55], where $\mathrm{Y}_{\mathrm{H}_{2} \mathrm{O}}$ experiences two step-change increases that are distinct, monotonic, and correspond to the first and second stages of autoignition.

For $\mathrm{Y}_{\mathrm{OH}}$, significant values of $\mathrm{Y}_{\mathrm{OH}}$ are confined to a narrow band of $\xi$ values, centered about $\xi_{S T}$ at times experiencing HTC. This is in agreement with the qualitative results presented in section 3.1.

The conditional statistics presented here resemble the results of the $n$-heptane spray autoignition study by Borghesi et al. [37]. In that study, low and high-temperature branches were detected and the location of peak HRR was observed to move into richer $\xi$ values prior to the high-temperature ignition. The ignition kernels in that study formed at locations slightly richer than $\xi_{M R}$. Statistics of minor species associated purely with LTC were not presented and no mechanism was proposed for the pre-ignition behaviour in $\xi$ space. As detailed in Ref. [41], in the present study, the LTC 
controls the evolution of the conditional HRR statistics prior to the high-temperature ignition and this behaviour is also responsible for the formation of ignition kernels in richer-than-expected $\xi$ values.

These results show that three distinct states of progress (degree to which the mixture is oxidised) may coexist for cases with two-stage autoignition: mixing (unburnt) ${ }^{1}$, LTC (partially burnt), and HTC (burnt). This is in addition to the initially bimodal distribution of $\xi$, and may present a modelling challenge, e.g., for combustion models which presume a PDF for progress variable $[56,57]$ that are usually monomodal (e.g. delta or Guassian distributions) or bimodal (e.g. beta distributions).

\subsection{Low-temperature chemistry and high-temperature ignition kernel formation}

A detailed analysis of the LTC behaviour and its influence on the formation of high-temperature ignition kernels was presented in a recent study [41]. For completeness and in order to understand the contributions of the present work, the main findings of the previous study need to be briefly recounted.

In Ref. [41], statistics of HRR doubly conditioned upon $\xi$ and $\chi$ showed that LTC initially develops at approximately $\xi=\xi_{M R, 1}$ (the homogeneous most reactive mixture fraction of the first stage of ignition) and $t=\tau_{1}$ (the shortest homogeneous ignition delay time of the first stage of ignition) in isolated regions with low $\chi$. The initial LTC HRR was therefore attributed to the first stage of autoignition. The sensitivity to $\chi$ was similar to that observed for the ignition of singlestage mixtures at non-diesel-relevant conditions [5]. At later times, the doubly conditioned results showed a qualitative change in behaviour such that the HRR was relatively insensitive to $\chi$ (for $\chi<5001 / \mathrm{s}$ ). In fact, the results suggested that the movement of LTC into richer mixtures was promoted by higher levels of $\chi$ (for $\chi<5001 / \mathrm{s}$ ).

To clarify the transition in LTC behaviour, a transport budget analysis [58] of the LTC species mass fraction $\mathrm{Y}_{\mathrm{CH}_{3} \mathrm{OCH}_{2} \mathrm{O}_{2}}$ at early $\left(\mathrm{t}^{*}=0.4\right)$ and late $\left(\mathrm{t}^{*}=0.8\right)$ times was conducted. At $\mathrm{t}^{*}=$ 0.4, the budgets were dominated by the reaction term which was much larger than the diffusion

\footnotetext{
${ }^{1}$ Although the mixing state is quickly diminished in this case, it should be expected to be more pronounced in diesel jet flames where the presence of large-scale entrainment can introduce unburnt mixture. This is not present in this simulation but is present at actual diesel conditions.
} 

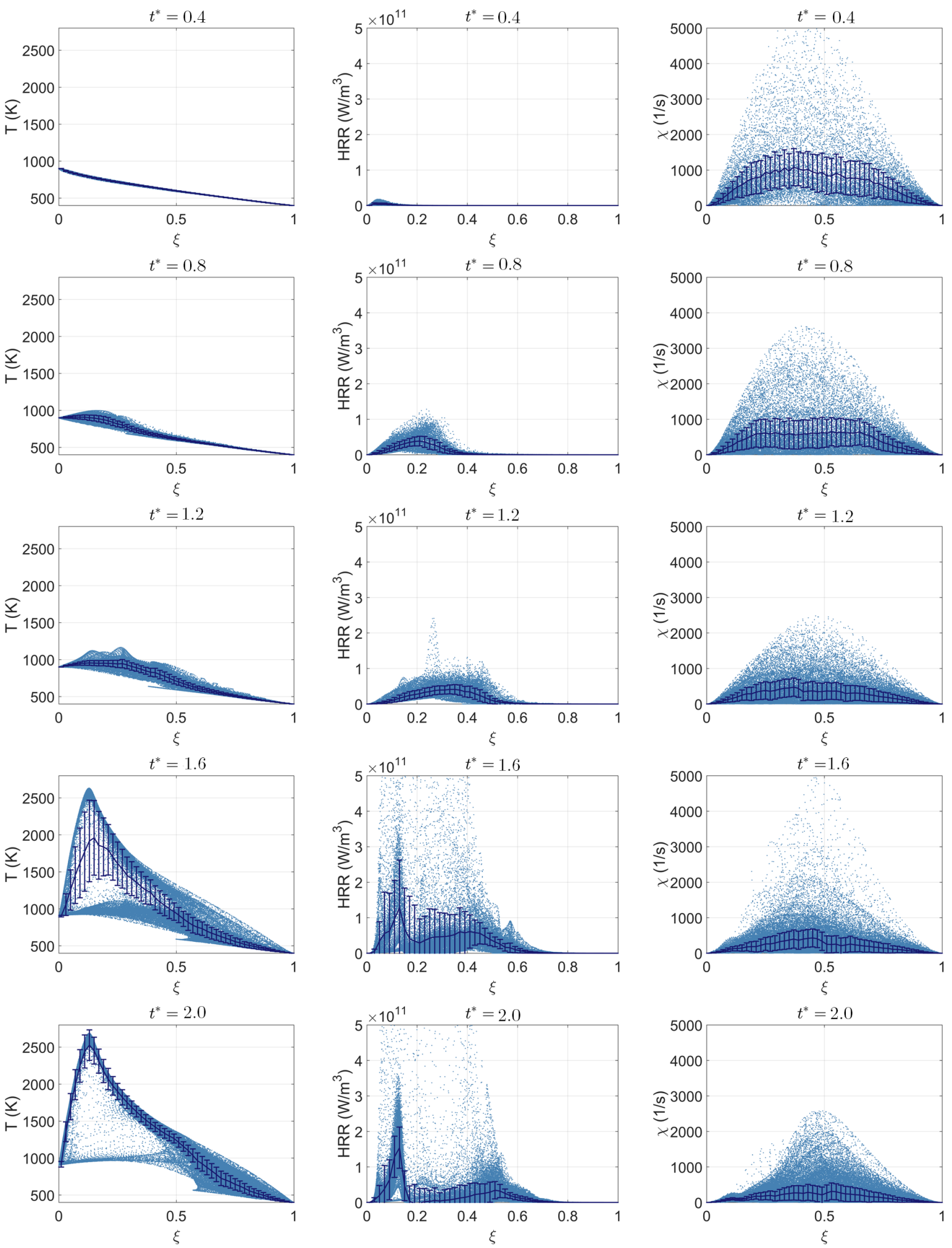

Figure 4: Evolution of statistics for T (left column), HRR (middle column), and $\chi$ (right column). Statistics evaluated at intervals of $\tau_{E}$, each row represents one instant in time. Scatter data shows samples evaluated over domain, line data is the mean value conditioned on $\xi$, error bars show plus and minus 1 standard deviation from the conditional mean. 

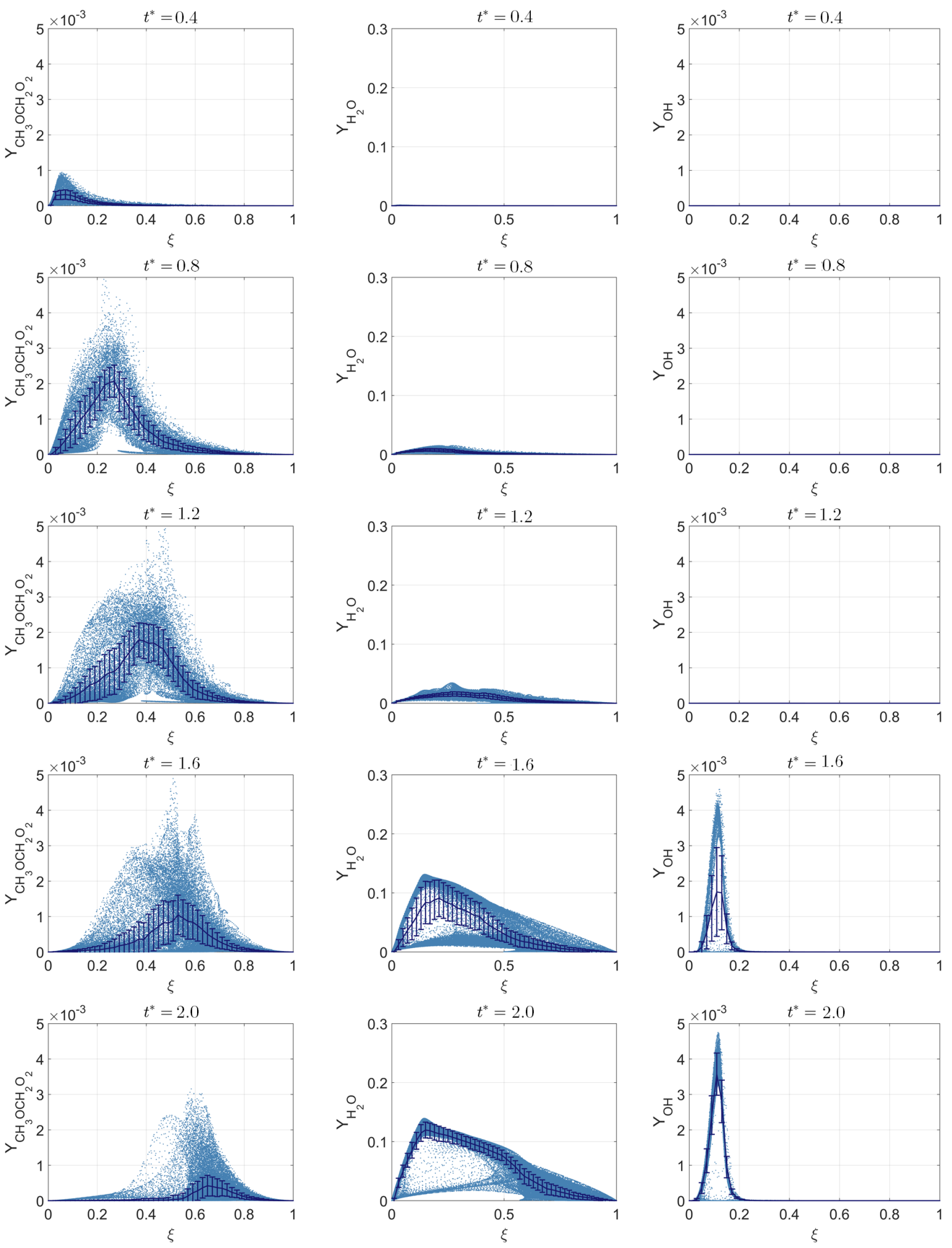

Figure 5: Evolution of statistics for $\mathrm{Y}_{\mathrm{CH}_{3} \mathrm{OCH}_{2} \mathrm{O}_{2}}$ (left column), $\mathrm{Y}_{\mathrm{H}_{2} \mathrm{O}}$ (middle column), and $\mathrm{Y}_{\mathrm{OH}}$ (right column). Statistics evaluated at intervals of $t^{*}=0.4$, each row represents one instant in time. Scatter data shows samples evaluated over domain, line data is the mean value conditioned on $\xi$, error bars show plus and minus one standard deviation from the conditional mean. 
term, confirming that the LTC was initially due to the first stage of autoignition. At $\mathrm{t}^{*}=0.8$, the budget involved a balance between reaction and diffusion in thin layers, indicating that the LTC had transitioned into diffusively supported "cool flames".

The cool flame location was defined based on a LTC species threshold. The species $\mathrm{Y}_{\mathrm{OCH}_{2} \mathrm{OCHO}}$ was selected to delineate the cool flame as it is a very short-lived radical species only associated with LTC reactions. The cool flame was defined to reside in regions where $\mathrm{Y}_{\mathrm{OCH}_{2} \mathrm{OCHO}}>2.21 \times 10^{-5}$ (20\% of the maximum observed value). This threshold was suitable as it excluded regions both nonreacting regions and regions reacting due to HTC. The mean location of the cool flame in $\xi$-space was calculated, and its movement over time was compared to $\tau, \tau_{1}$, and the formation of the hightemperature ignition kernels. These results are reproduced here in Fig. 6. It was observed that the cool flame proceeds much more rapidly into richer mixtures compared to the gradient of first-stage ignition delay times. This leads to an earlier onset of both LTC and HTC reactions compared to a homogeneous reactor results. The effect become increasingly prominent at richer mixtures.

The main finding in Ref. [41] was the discovery of this cool flame mechanism that affected

the high-temperature ignition at diesel engine-relevant conditions. This mechanism explains why the high-temperature ignition kernels form in mixtures richer than expected from homogeneous calculations and the result was broadly consistent with existing experimental measurements $[1,3]$ and RANS modelling of igniting diesel jets [4].

\subsection{Transition from kernel to edge flame}

Throughout the simulation, 18 independent kernels are observed. The ensemble of autoignition kernels in the present study is qualitatively similar to the experimental results from Merkides and Mastorakos [14-16] and Papageorge [18]. Markides and Mastorakos visualised kernel formation and development for pipe-flows with a mean bulk velocity. In those studies, a "random spots" regime was observed in which a flame was stabilised via a rapid sequence of isolated autoignition kernels which later became extinguished. In the present study, the kernels do not become extinguished and instead grow until they cross the $\xi_{S T}$ iso-surface and establish structures that resemble the tetrabrachial edge flames observed in Refs. [38-40].

A similar transition, from kernel to tribrachial edge flames, has been previously observed in a 


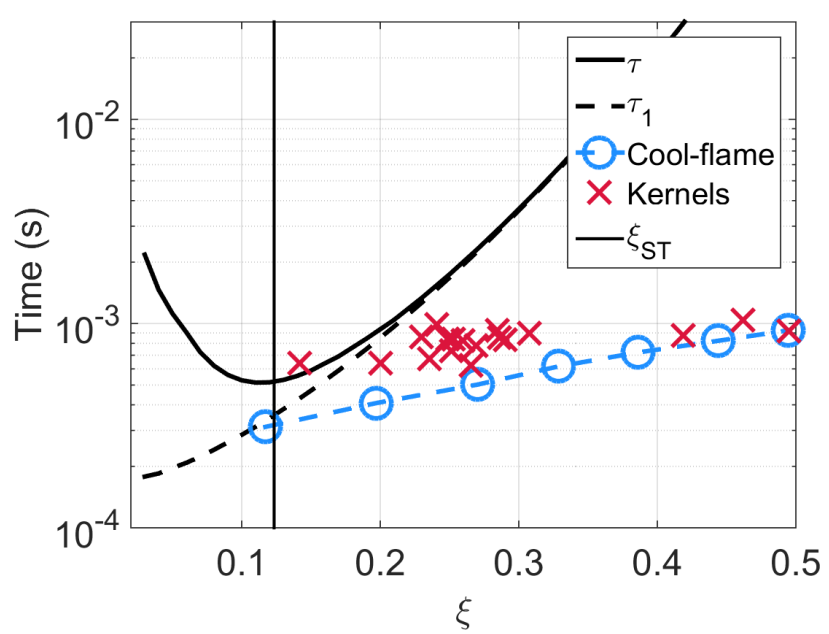

Figure 6: A plot of homogeneous ignition delay times (solid black line is $\tau$ and dashed black line is $\tau_{1}$ ) alongside the movement of the mean cool flame location (blue dashed lines with circle symbols) and the formation of hightemperature ignition kernels (red cross symbols). This result suggest that the cool flame advances both the onset of LTC and HTC chemistry and this effect is more pronounced at richer mixtures. This figure is reproduced from Ref. $[41]$.

hydrogen lifted flame DNS [17] and a simple chemistry mixing layer DNS study [53]. The results from Kerkemeier et al. [17] were qualitatively different to the present result because a transition from kernel formation to a continuously burning flame were not observed. This difference may be attributed to: the mean bulk flow in that study, which is absent in the present study and may cause ignition kernels to be convected out of the domain before a continuous flame may be established; the existence of NTC effects such as the cool flame and two-stage ignition which may promote the edge flame propagation behaviour and suppress kernel extinction; and/or the low turbulent intensity and 2D configuration used in the present study, which may prevent the extinction of ignition kernels.

In order to investigate the structure of these flames, a transport budget analysis $[25,58]$ is conducted for a key HTC intermediate, the hydroxyl radical $(\mathrm{OH})$. The transport budget analysis is performed by evaluating and comparing the terms in the transport equation for $\mathrm{Y}_{\mathrm{OH}}$ :

$$
\frac{\partial \rho Y_{O H}}{\partial t}=-\nabla_{j} \cdot\left(\rho Y_{O H} \mathbf{u}_{\mathbf{j}}\right)+\nabla_{j} \cdot\left(\rho Y_{O H} \mathbf{V}_{O H, j}\right)+W_{O H} \omega_{\dot{O} H}
$$

where the $j$ subscript denotes directional coordinates, $\mathbf{V}_{O H, j}$ is the diffusion velocity of $\mathrm{Y}_{\mathrm{OH}}$ in the $j$ direction, $W_{O H}$ is the molecular weight of of $\mathrm{Y}_{\mathrm{OH}}$, and $\omega_{\mathrm{OH}}$ is the molar reaction rate of $\mathrm{Y}_{\mathrm{OH}}$. The left hand side term is the time rate of change and the right hand side terms correspond to (from 
left to right): convection, diffusion, and chemical reaction. By comparing the relative magnitude of the diffusion and reaction terms, it is possible to distinguish between autoignition and flames. For autoignition, the reaction term is much larger in magnitude than the diffusion term; for flames, a balance is expected between reaction and diffusion ${ }^{2}[25,58,59]$.

Figure 7 presents a transport budget analysis for $\mathrm{Y}_{\mathrm{OH}}$, as well as the scalar dissipation rate. The evaluations are performed along lines normal to the reaction front. Lines marked from $\mathbf{A}$ to $\mathbf{F}$ are evaluated. Line $\mathbf{A}$ is evaluated through a kernel at the moment it is first detected. The diffusion term is much smaller than the reaction term and the $\chi$ value is very low, as expected for autoignition. Line $\mathbf{B}$ is taken through an expanding front following the formation of another ignition kernel. Although recently triggered through autoignition, this front has a reaction-diffusion balance and a very thin reaction zone associated with the propagation of a premixed flame. Line $\mathbf{B}$ resembles the structure of line $\mathbf{E}$, which is evaluated through the rich premixed branch of the nearby edge flame. The magnitude of the reaction-diffusion balance is much more intense for line $\mathbf{B}$ compared to line $\mathbf{E}$, which is attributed to their opposite direction of propagation (line $\mathbf{B}$ is moving towards, and line $\mathbf{E}$ away from, the $\xi_{S T}$ surface). Line $\mathbf{C}$ is taken through the trailing nonpremixed flame behind the edge flame. This region has high rates of formation of $\mathrm{Y}_{\mathrm{OH}}$ and a reaction-diffusion balance, but occupies a much broader region of space compared to the premixed branches corresponding to lines B, D, and E. Line D is evaluated through the lean premixed branch which is less vigorous than the rich premixed branch (as measured by local HRR). Line $\mathbf{F}$ is taken through the triple point of an edge flame. At the leading edge of the edge flame, a premixed structure is observed, behind which trails a region of $\mathrm{Y}_{\mathrm{OH}}$ formation associated with the nonpremixed flame.

Overall, the budget analysis confirms that the kernels rapidly transition to rich premixed flames which establish edge flames where they engulf the $\xi_{S T}$ surface. These flames are not simply autoignition fronts but involve significant amounts of molecular diffusion. The edge flames have a tetrabrachial structure reminiscent of the lifted flames observed in Refs. [38-40].

The premixed flames (e.g. at $\mathbf{B}, \mathbf{E}$, and $\mathbf{F}$ ) are associated with significant peaks in $\chi$. These

\footnotetext{
${ }^{2}$ Note that in typical hydrocarbon premixed flames in atmospheric conditions, distinct convection-diffusion and diffusion reaction zones are observed. This is a consequence of high activation temperatures relative to atmospheric temperature; however, in the present situation a distinct convective-diffusive zone is not necessarily expected due to the autoignitive ambient condition ahead of the flame.
} 
peaks correspond to the appearance of high $\chi$ scatter points in Fig. 4 following the high-temperature ignition. This result is consistent with an NTC-affected mixing layer ignition study conducted by Mukhopadhyay and Abraham [35]. In that study, a peak in $\chi$ was observed in $\xi$ space corresponding to the leading edge of an expanding ignition, but the structure of the flame was not described in terms of its transport budget. In the present case, the spatial profile of the transport budget and $\chi$ across the premixed flame features identifies the location of the transient peak values of $\chi$. As previously discussed [35], the modification to the statistics of $\chi$ conditioned upon $\xi$ should be expected to impact the accuracy of laminar flamelet models which presume a relationship between $\chi$ and $\xi$ that does not take into account the increased intermittency of $\chi$.

\subsection{Edge flames}

The role of edge flames in diesel-relevant conditions may depend upon the edge flame propagation speed and its response to fluctuations in $\chi$ and the partially reacted mixture. Several edge flames develop in the present DNS due to the expansion of the ignition kernels. The edge flames have a hybrid structure consisting of a main tribrachial (triple) flame that moves into an additional lowtemperature branch. The tribrachial flame consists of a crescent-shaped leading edge with rich and lean branches and a trailing nonpremixed (diffusion) flame. The premixed nature of the leading edge causes it to propagate into the partially reacted mixture, where the cool flame resides. The cool flame merges into the tribrachial flame, forming a tetrabrachial (quadruple) flame.

An important edge flame parameter is the displacement speed, $\mathrm{S}_{d}$, which is defined by the movement of a scalar iso-surface that corresponds to the edge flame reaction front. For a given surface of a given species, the displacement speed is defined as [60]

$$
S_{d}=\frac{1}{\rho\left|\nabla Y_{k}\right|}\left(-\dot{\omega}_{k}-\nabla \cdot\left(\rho D \nabla Y_{k}\right)\right)
$$

where $\rho$ is the density, $\dot{\omega}_{k}$ is the reaction rate of species $k$, and D is the thermal diffusivity. The first term on the right hand side is due to reaction, $\mathrm{S}_{d_{R}}$, and the second term is due to diffusion, 

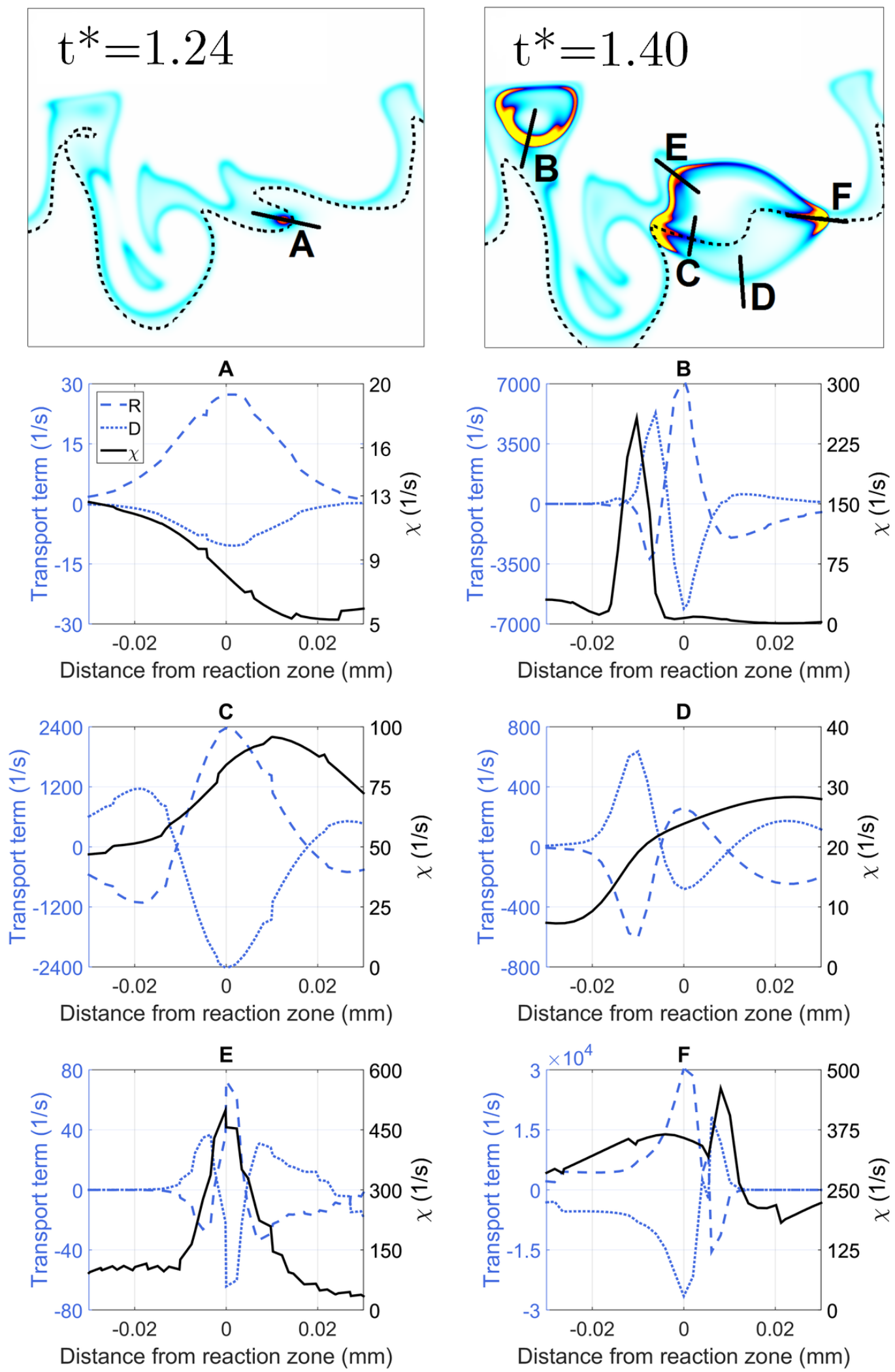

Figure 7: Evaluation of budget transport terms and $\chi$ along lines normal to reaction fronts. Top left figure shows HRR field at $t^{*}=1.24$ when an ignition kernel is first detected. Top right figure shows HRR field at $t^{*}=1.40$, after first kernel has established edge flames and a second kernel has formed (near location B). The dashed black line in the top row of figures is $\xi_{S T}$. The figures labelled from $\mathbf{A}$ to $\mathbf{F}$ represent the evaluations of diffusion (D), reaction (R) and $\chi$ along lines indicated on the top row of figures. Note than the axes are not uniformly scaled. 
$\mathrm{S}_{d_{D}}$. The diffusion term can be further decomposed [61] as

$$
\frac{\nabla \cdot\left(\rho D \nabla Y_{k}\right)}{\rho\left|\nabla Y_{k}\right|}=\frac{\frac{\partial}{\partial \eta}\left(\rho D \frac{\partial Y}{\partial \eta}\right)}{\rho|\nabla Y|}+D(\nabla \cdot \mathbf{n})
$$

where $\eta$ is the flame normal coordinate and $\mathbf{n}$ is the flame normal unit vector. The first term on the right hand side is the component of diffusion normal to the flame, $\mathrm{S}_{d_{N}}$, and the second term is the component of diffusion tangential to the flame (the curvature term), $\mathrm{S}_{d_{C}}$. Here the iso-surface $\mathrm{Y}_{\mathrm{H}_{2} \mathrm{O}}=0.08$ is used to evaluate the displacement speed and its components.

Statistics of $\chi$ and $\mathrm{S}_{d}$ were gathered at the triple point for all edge flames and times. The triple point is the location where the lean premixed, rich premixed, and nonpremixed branches of the edge flame meet. This location is defined here by the intersection of the $\xi_{S T}$ iso-contour and the iso-contour of $\mathrm{Y}_{\mathrm{H}_{2} \mathrm{O}}=0.08$, which is coincident with the maximum HRR on the premixed branches. Figure 8 presents the means and scatter of $\mathrm{S}_{d}$ and its components, conditioned upon $\chi$. Similar to tribrachial edge flames at atmospheric conditions [62-66], increasing $\chi$ reduces $\mathrm{S}_{d}$. This trend is explained by the increase in the magnitude of the $\mathrm{S}_{d_{C}}$ term, as was previously concluded in Ref. [65]. The higher values of $\chi$ are associated with steeper composition gradients in the vicinity of the triple point, simultaneously reducing the premixedness and increasing the edge flame's curvature.

A major difference in this case compared to previous studies of edge flame propagation for single stage fuels is that the mixture through which the edge flames are propagating is partially reacted. The first stage of autoignition, which leads to the passage of the cool flame, causes a rise in temperature and a change in the chemical composition of the mixture compared to the initial condition. A location just upstream of the triple point is therefore defined in order to consider the chemical state of the mixture just ahead of the edge flames. The location is defined to be two thermal thicknesses ahead of the triple point, measured along the $\xi_{S T}$ iso-contour. The thermal thickness, $\delta_{T}$, is defined as $\delta_{T}=\left(\mathrm{T}_{b}-\mathrm{T}_{u}\right) / \max (\partial \mathrm{T} / \partial \mathrm{x}) \approx 20$ microns. Figure 9 shows an example edge flame location and the upstream location. Ahead of the edge flames, the mixture can be characterised by a progress variable. Here, the mass fraction of $\mathrm{Y}_{\mathrm{H}_{2} \mathrm{O}}$ is used as a progress variable. As previously stated in section 3.2, $\mathrm{Y}_{\mathrm{H}_{2} \mathrm{O}}$ increases monotonically in response to both LTC and HTC reactions across a laminar flame profile, commensurate with the temperature increase profile, making it a 
suitable selection for progress variable.

Figure 10 presents statistics of $S_{d}$ and its components, conditioned upon the upstream progress variable. Most of the $\mathrm{S}_{d}$ data resides between 2.0 and $3.5(\mathrm{~m} / \mathrm{s})$, which compares with order $10(\mathrm{~m} / \mathrm{s})$ axial velocities measured at the stabilisation location in RANS transported probability density function (TPDF) simulations of diesel jets $[4,67]$. Since turbulent flames can propagate in net much faster than local flamelets, this comparison implies that edge flames in these conditions have sufficient velocities to be potentially involved in diesel flame stabilisation.

In Fig 10, there is a clear trend of increasing $\mathrm{S}_{d}$ with increasing upstream progress variable. Considering the components of $\mathrm{S}_{d}$, both the $\mathrm{S}_{d_{R}}$ and $\mathrm{S}_{d_{N}}$ terms are very weakly affected by the upstream progress variable while $S_{d_{C}}$ is positively correlated with increasing upstream progress variable. The results show a correlation between the upstream progress of chemical reaction and the edge flame propagation speed, which is mostly attributed to the $\mathrm{S}_{d_{C}}$ term.

The dependencies of $S_{d}$ on the local $\chi$ and the upstream progress variable appear to be related effects, since both parameters are themselves strongly negatively correlated such that high values of upstream progress variable are associated with low values of $\chi$ at the triple-point and vice versa (not shown here). Since the correlation of displacement speed with both $\chi$ and the upstream progress variable are due mostly to the curvature term (and not the reaction term), it appears likely that it is the effect of $\chi$ which is the controlling parameter. That is, high $\chi$ both limits the upstream progress and increases the curvature, where the latter is responsible for the $\mathrm{S}_{d}$ dependence on $\chi$ rather than the former.

\subsection{Combustion mode analysis}

Experimental imaging results indicate that diesel combustion is a multi-stage, multi-mode process [1-3]. The autoignition event occurs as a two-stage processes consisting of a first (LTC) and second (HTC) stage of autoignition, which leads to a quasi-stabilised lifted flame (for conventional diesel conditions) that consists of spatially segregating regions of LTC (autoignition or cool flame), rich premixed combustion, and a nonpremixed flame $[2,3]$. These findings chiefly draw upon imaging of key chemical species such as hydroxyl radical $\mathrm{OH}$ and formaldehyde $\mathrm{CH}_{2} \mathrm{O}$; however, such measurements are limited in terms of: spatial and temporal resolution; the separation of scales in 

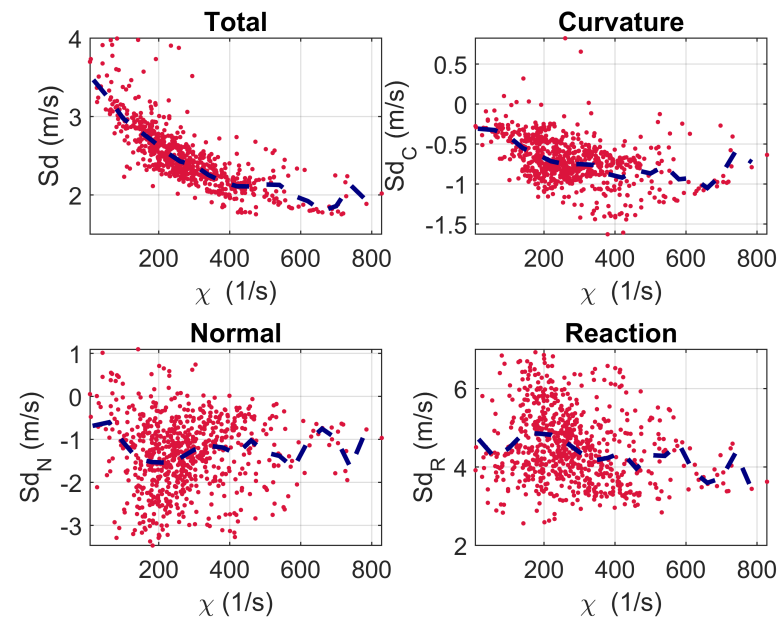

Figure 8: Statistics for $\mathrm{S}_{d}$ and its terms, conditioned upon $\chi$, evaluated at the edge flame triple point. The red dots are the sample values, the blue dashed line is the conditional mean.

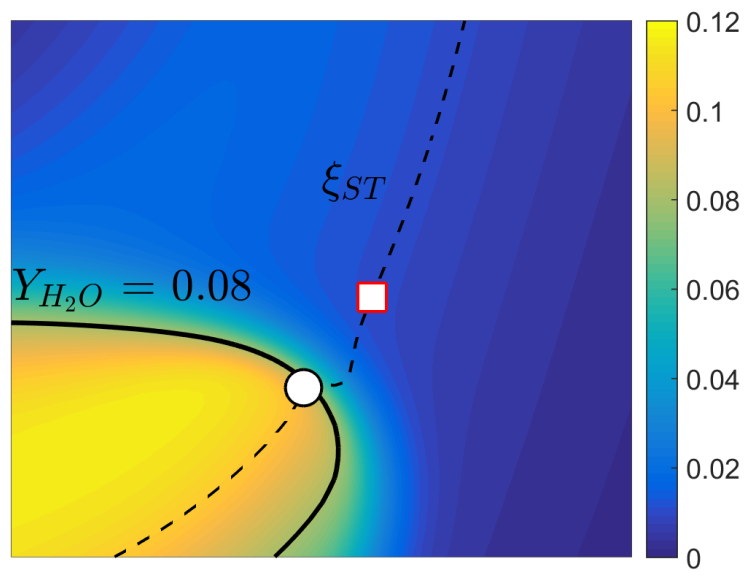

Figure 9: Example edge flame and upstream location. The colour shading measures $\mathrm{Y}_{\mathrm{H}_{2} \mathrm{O}}$ and the critical value of 0.08 is marked in the bold black line, which coincides with the peak HRR near the edge flame triple point. The black dashed line marks the $\xi_{S T}$ iso-contour and the edge flame triple point is located where the two lines intersect, marked by the white circle. The upstream location is two thermal thicknesses upstream of the triple point, measured along the $\xi_{S T}$ iso-contour, marked by the white square with the red border. The figure shows a $0.1 \times 0.1 \mathrm{~mm}$ instantaneous window of the domain. 

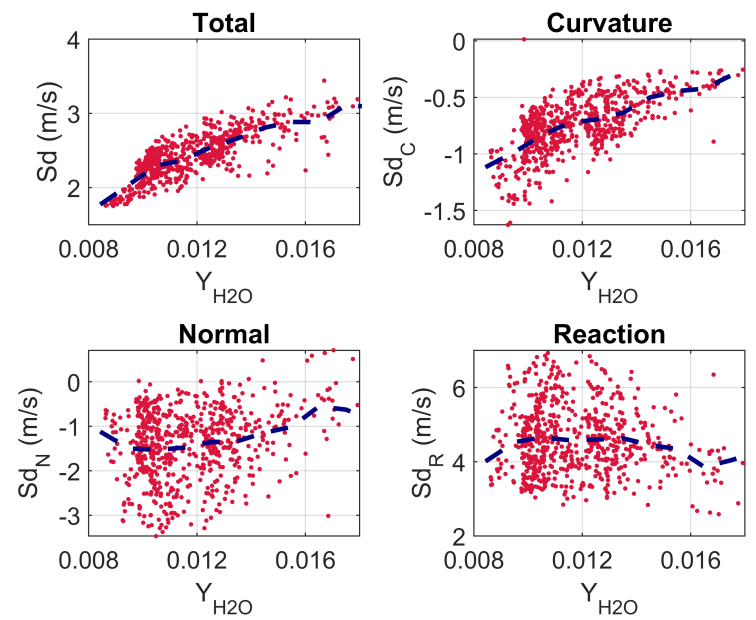

Figure 10: Statistics for Sd and its terms, conditioned upon $\chi$, evaluated ahead of the edge flame. The red dots are the sample values, the blue dashed line is the conditional mean.

signal intensity (which makes certain simultaneous measurements difficult) [68]; signal attenuation due to sooting; and difficulties in observing weakly emitting minor species. The use of DNS in the present study avoids all of these limitations. By carefully selecting appropriate markers, distinct combustion modes may be defined and identified within the results. In this section, a combustion mode analysis is conducted that classifies combustion (as measured by HRR) over the entire domain and for the duration of the simulation.

In order to delineate between the combustion modes, an analysis based on key chemical species is conducted. As seen in Figs. 1 and 2: $\mathrm{Y}_{\mathrm{CH}_{3} \mathrm{OCH}_{2} \mathrm{O}_{2}}$ is closely associated with the LTC HRR, a $\mathrm{Y}_{\mathrm{H}_{2} \mathrm{O}}$ threshold can identify regions of HTC, and high levels of $\mathrm{Y}_{\mathrm{OH}}$ are confined to burning regions of the $\xi_{S T}$ surface. Using these observations, it is possible to decompose the total HRR into the following modes:

- $\mathcal{M}_{L T C}$ - regions of LTC, associated with either the first stage of autoignition or the passage of the cool flame. This mode is defined as: $\mathcal{M}_{L T C}=\mathrm{Y}_{\mathrm{CH}_{3} \mathrm{OCH}_{2} \mathrm{O}_{2}}>\left.\mathrm{Y}_{\mathrm{CH}_{3} \mathrm{OCH}_{2} \mathrm{O}_{2}}\right|_{C R I T}$.

- $\mathcal{M}_{H T C-l e a n}$ - regions of HTC, associated with the lean premixed branches of the edge flames. Defined as: $\mathcal{M}_{H T C-\text { lean }}=\mathrm{Y}_{\mathrm{CH}_{3} \mathrm{OCH}_{2} \mathrm{O}_{2}}<\left.\mathrm{Y}_{\mathrm{CH}_{3} \mathrm{OCH}_{2} \mathrm{O}_{2}}\right|_{C R I T} \cap \mathrm{Y}_{\mathrm{OH}}<\left.\mathrm{Y}_{\mathrm{OH}}\right|_{C R I T} \cap \xi<\xi_{S T}$.

- $\mathcal{M}_{H T C-\text { rich }}$ - regions of HTC, associated with the rich premixed branches of the edge flames and the growth of kernels. $\mathcal{M}_{H T C-\text { rich }}=\mathrm{Y}_{\mathrm{CH}_{3} \mathrm{OCH}_{2} \mathrm{O}_{2}}<\left.\mathrm{Y}_{\mathrm{CH}_{3} \mathrm{OCH}_{2} \mathrm{O}_{2}}\right|_{C R I T} \cap \mathrm{Y}_{\mathrm{OH}}<\left.\mathrm{Y}_{\mathrm{OH}}\right|_{C R I T}$ 
$\cap \xi>\xi_{S T}$

- $\mathcal{M}_{H T C-d i f f}$ - regions of HTC, associated with the nonpremixed flame centred on the $\xi_{S T}$ surface. Defined as: $\mathcal{M}_{H T C-d i f f}=\mathrm{Y}_{\mathrm{CH}_{3} \mathrm{OCH}_{2} \mathrm{O}_{2}}<\left.\mathrm{Y}_{\mathrm{CH}_{3} \mathrm{OCH}_{2} \mathrm{O}_{2}}\right|_{C R I T} \cap \mathrm{Y}_{\mathrm{OH}}>\left.\mathrm{Y}_{\mathrm{OH}}\right|_{C R I T}$.

The critical value of $\mathrm{Y}_{\mathrm{CH}_{3} \mathrm{OCH}_{2} \mathrm{O}_{2}},\left.\mathrm{Y}_{\mathrm{CH}_{3} \mathrm{OCH}_{2} \mathrm{O}_{2}}\right|_{C R I T}=3 \times 10^{-5}$, was selected to isolate LTC regions. The critical value of $\mathrm{Y}_{\mathrm{OH}},\left.\mathrm{Y}_{\mathrm{OH}}\right|_{C R I T}=2.5 \times 10^{-4}$, was selected to isolate the nonpremixed flame from the premixed burning. These critical values are $5 \%$ of their respective peak local, instantaneous values. While the choice of threshold value does somewhat influence the combustion mode classification, the outcome is not very sensitive to the choice of threshold values, as judged by a sensitivity analysis (not shown here).

The definitions for the combustion modes presented here avoid double-counting regions of chemical reaction, and include all chemically active mixtures. The sum of the HRR of all modes equals the overall total HRR.

Figure 11 shows example images at various time instants of the domain coloured by combustion mode. Note that regions below a lower HRR threshold of $1 \times 10^{8}\left(\mathrm{~W} / \mathrm{m}^{3}\right)$ are transparent (appear white) in order to improve the clarity of the image. The results follow from the chemical features presented in Fig. 2, but in this figure it is much easier to distinguish combustion modes and to discern features of interest. At $\mathrm{t}^{*}=1.2$, the cool flame is observed as well as the formation of an ignition kernel. This kernel grows and establishes an edge flame by $t^{*}=1.4$. As the simulation progresses, multiple edge flames are observed. The triple points are identifiable by the meeting point of the HTC modes with the $\xi_{S T}$ surface, which move into the $\mathcal{M}_{L T C}$ regions. The $\mathcal{M}_{H T C-\text { rich }}$ mode moves into richer $\xi$ and consumes the $\mathcal{M}_{L T C}$ regions. By $\mathrm{t}^{*}=2.2$, the entire $\xi_{S T}$ surface is marked as $\mathcal{M}_{H T C-\text { diff }}$ and very little $\mathcal{M}_{L T C}$ remains.

The evolution of the combustion modes is represented in Fig. 12 by integrating the local HRR over the domain for each mode. The result shows that the simulation can be classified into four distinct stages. Stage I is an induction period, lasting approximately one eddy turn over time, in which very little HRR is observed. Stage II is dominated by $\mathcal{M}_{L T C}$, in which the first stage of autoignition transitions to a cool flame which steadily increases the HRR in the domain, this lasts for just under two eddy turn over times. During this stage the $\mathcal{M}_{L T C}$ moves into richer mixtures. 
Stage III is initiated by the formation of $\mathcal{M}_{H T C-\text { rich }}$ regions, associated with the ignition kernels, which rapidly establish $\mathcal{M}_{H T C-d i f f}$ and $\mathcal{M}_{H T C-\text { lean }}$ modes via edge flame propagation. Stage III is marked by a rapid increase in HRR and a gradual tapering of $\mathcal{M}_{L T C}$. Stage IV begins when the HRR peaks and then rapidly declines until the end of the simulation. During this stage the premixed and LTC modes decrease while the nonpremixed mode remains steady. These stages can be broadly classified as: induction, cool flame, ignition, and burnout.

The $\mathcal{M}_{L T C}$ mode accounts for a significant fraction (24\%) of the overall heat released. This number would be lower if the simulation was not truncated prior to the complete fuel burnout, however, it suggests the possibility that the LTC reactions may be provide a very significant contribution to the overall oxidation of the fuel, and may therefore be an important process to model appropriately.

The bulk of HTC HRR in the simulation is attributed to either $\mathcal{M}_{\text {HTC-diff }}$ or $\mathcal{M}_{\text {HTC-rich }}$. Initially, the HTC occurs in the $\mathcal{M}_{H T C-r i c h}$ mode, which is consistent with conceptual models that identify a rich premixed burn prior to flame stabilisation (associated with the spatially distributed autoignition). Later, the edge flames establish the $\mathcal{M}_{H T C-d i f f}$ mode, which rapidly overtakes the $\mathcal{M}_{H T C-\text { rich }}$ mode, which is consistent with conceptual models that depict spatially segregated regions of nonpremixed and rich premixed combustion, without a distinct lean premixed region.

Overall, stages I to IV observed here are broadly consistent with conceptual models of conventional diesel combustion. In particular, the conceptual model presented by Musculus et al. [3] describes both the autoignition and quasi-stable stages of combustion, which states that (following the vapourisation of the fuel jet) a dwell period occurs prior to a two-stage ignition that transitions to a quasi-steady lifted flame. The lifted flame is primarily composed of a nonpremixed mode and a rich premixed mode and a small region of LTC exists upstream of the stabilisation location. Following the end of injection, burnout occurs as the remaining fuel is consumed.

The correspondence between experimental observations and the present analysis is encouraging. Combustion mode analysis may be a useful diagnostic tool that could be applied to future numerical simulations, under more representative conditions. This has the potential to assist with the improvement of conceptual models, and the measurement of quantities conditioned upon combustion mode, for example pollutant formation and fuel consumption. 

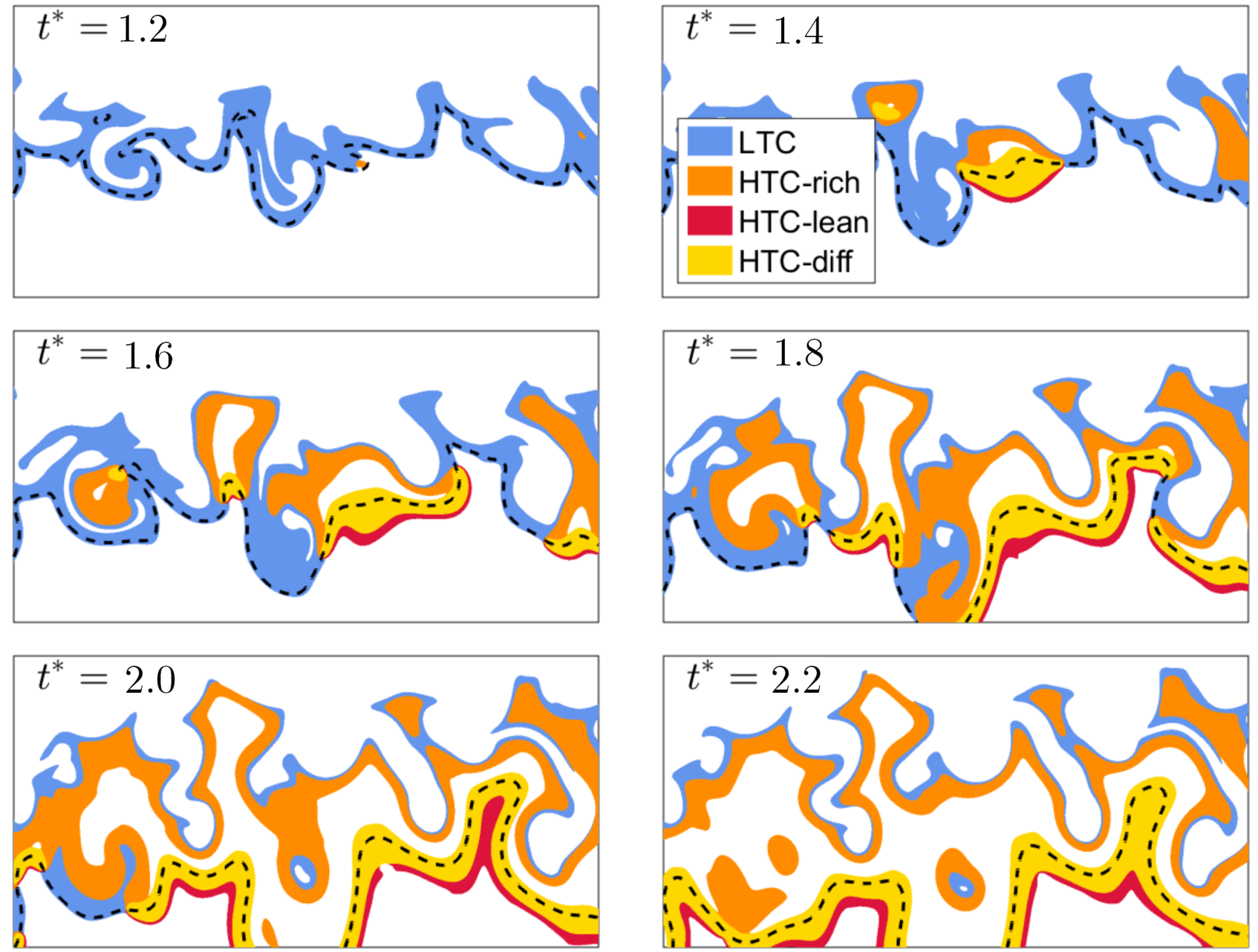

Figure 11: Region of domain in time, coloured by combustion mode. The black dashed line is the $\xi_{S T}$. The top of the image (above the black dashed line) is fuel rich, the bottom of the image is fuel lean.

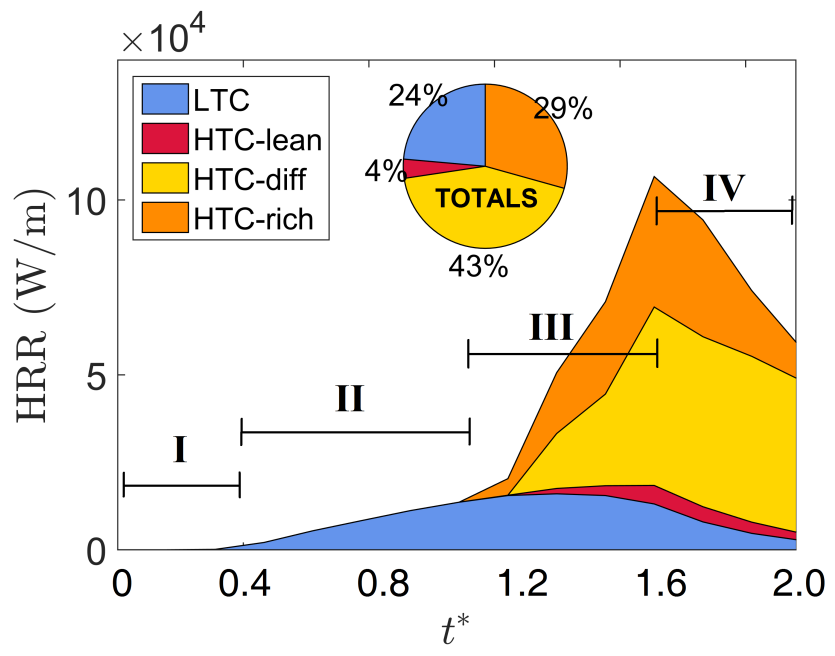

Figure 12: Contributions of each mode of combustion to the overall HRR. The pie chart inset shows the total relative contribution from each mode. 


\section{Conclusions}

A direct numerical simulation (DNS) of diesel engine-relevant ignition was conducted under idealised conditions. The computational domain was a two-dimensional mixing layer of dimethyl ether (DME) and air with a spectrum of isotropic pseudo turbulence imposed as an initial condition in order to match the Damkhöler number estimated at the flame base of a diesel jet. The thermochemical conditions were selected in order to approximate a diesel-relevant environment.

The ignition occurred as a multi-stage and multi-mode process. A two-stage autoignition event occurred that led to the formation of hybrid edge flame/autoignitiion structures. As detailed in a prior study based on the same DNS data set [41], the low-temperature chemistry (LTC) is initially due to the first stage of autoignition before it transitions into a diffusively supported cool flame that shortens the ignition delay times preferentially at richer mixtures, introducing a rich ignition bias compared to simulations at homogeneous conditions. The present study extended the previous analysis to completely characterise the overall ignition process, including the nature of the hightemperature ignition kernels and the propagation of the hybrid edge flames.

A transport budget analysis demonstrated that the expanding ignition kernels rapidly transition to rich premixed flames which generate locally high values of scalar dissipation rate which introduced intermittency to the PDFs of $\chi$. Where these flames cross the stoichiometric mixture fraction surface, they establish hybrid edge flame/autoignition structures. The transition from ignition kernel formation to edge flame propagation is driven by a diffision-reaction balance; it does not act as an autoignition front. The edge flames have a main tribrachial (triple) flame structure which is composed of leading crescent-shaped lean and rich premixed branches, connected to a trailing nonpremixed flame at the triple-point. A LTC branch exists ahead of the premixed branches that is associated with the cool flame. The edge flame is therefore a tetrabrachial (quadruple) flame which is similar to that reported for diesel-relevant lifted laminar flames [38-40].

The displacement speed of the edge flames were measured with respect to the local scalar dissipation rate and the upstream reaction progress variable. The displacement speeds ranged from about 2.0 to $3.5(\mathrm{~m} / \mathrm{s})$, which is of similar magnitude to calculations obtained at the stabilisation location of diesel jets from RANS TPDF calculations [4]. A negative correlation with $\chi$ and a 
positive correlation with $\mathrm{Y}_{\mathrm{H}_{2} \mathrm{O}}$ was observed. An examination of the displacement speed components showed that these correlations could be explained by the curvature terms and not the reaction terms. This suggests that the both the displacement speed and upstream value of $\mathrm{Y}_{\mathrm{H}_{2} \mathrm{O}}$ are influenced by the local mixing rates.

A combustion mode analysis, based on a consideration of the distribution of key chemical species was conducted in order to identify and classify the distinct combustion modes involved in the overall ignition. Four modes of combustion were identified by classifying local HRR based upon the local chemical composition of key species. The four combustion modes identified were: LTC, lean premixed HTC, rich premixed HTC, and nonpremixed HTC. By decomposing the HRR into combustion modes, the complex multi-mode and multi-stage overall process observed in the simulation was clarified. By considering the domain-wide evolution of the combustion modes, the simulation was divided into four stages: an induction phase with little chemistry, a cool flame stage with only LTC, an ignition phase in which the rich premixed and nonpremixed modes rapidly developed as the LTC mode waned, and a burnout phase in which the overall HRR declined and was increasingly dominated by the nonpremixed mode. This description is broadly consistent with conceptual models of diesel combustion, and may help to qualify and quantify processes in diesel combustion that are difficult to determine experimentally.

These results may be specific to the $2 \mathrm{D}$ and moderate $\mathrm{Re}_{T}$ number configuration of the present study. Additional studies are required that test the effects of: increased turbulence intensity, threedimensionality, shear-generated turbulence, and a spatially-developing jet configuration.

Overall, these results show that both autoignition and deflagration (edge flames) are important in the ignition process and can overlap in time scales. Furthermore, the ignition was observed to be a complex, multi-mode and multi-stage process involving LTC and HTC, and premixed and nonpremixed combustion. The results underscore the extreme modelling challenge presented by diesel combustion, even at the idealised conditions considered in the present study.

\section{Acknowledgements}

This work was supported by the Australian Research Council. The work at Sandia National Laboratories was supported by the Combustion Energy Frontier Research Center, an Energy Frontier 
Research Center funded by the US Department of Energy (DOE), Office of Science, Office of Basic Energy Sciences under Award No. DE-SC0001198. Sandia is a multiprogram laboratory operated by Sandia Corporation, a Lockheed Martin Company, for the United States Department of Energy under contract DE-AC04-94AL85000. The research was supported by computational resources on the Australian NCI National Facility through the National Computational Merit Allocation Scheme and Intersect Australia partner share and by resources at the Pawsey Supercomputing Centre.

\section{References}

[1] J.E. Dec, A conceptual model of DI diesel combustion based on laser-sheet imaging, SAE Paper 1997-97-0873,.

[2] C.A. Idicheria, L.M. Pickett, Formaldehyde visualization near lift-off location in a diesel jet, SAE Paper 2006-01-3434,.

[3] M.P.B. Musculus, P.C. Miles, L.M. Pickett, Conceptual models for partially premixed lowtemperature diesel combustion, Prog. Energ. Combust. Sci. 39 (2013) 246 - 283.

[4] Y. Pei, E.R. Hawkes, M. Bolla, S. Kook, G.M. Goldin, Y. Yang, S.B. Pope, S. Som, An analysis of the structure of an n-dodecane spray flame using TPDF modelling, Combust. Flame (in press) (2016) doi:10.1016/j.combustflame.2015.11.034.

[5] E. Mastorakos, Ignition of turbulent non-premixed flames, Prog. Energ. Combust. Sci. 35 (1) (2009) 57-97.

[6] E. Mastorakos, T.A. Baritaud, T.J. Poinsot, Numerical simulations of autoignition in turbulent mixing flows, Combust. Flame 109 (1997) 198 - 223.

[7] H.G. Im, J.H. Chen, C.K. Law, Ignition of hydrogen-air mixing layer in turbulent flows, Symp. (Int.) Combust. 27 (1) (1998) $1047-1056$.

[8] S. Sreedhara, K.N. Lakshmisha, Direct numerical simulation of autoignition in a non-premixed, turbulent medium, Proc. Combust. Inst. 28 (1) (2000) 25 - 33. 
[9] T. Echekki, J.H. Chen, Direct numerical simulation of autoignition in non-homogeneous hydrogen-air mixtures, Combust. Flame 134 (3) (2003) 169 - 191.

[10] A. Viggiano, A 2-D investigation of n-heptane autoignition by means of direct numerical simulation, Combust. Flame 137 (4) (2004) 432-443.

[11] X. Zheng, J. Yuan, C. Law, Nonpremixed ignition of H2-air in a mixing layer with a vortex, Proc. Combust. Inst. 30 (1) (2005) 415 - 421.

[12] S. Cao, T. Echekki, Autoignition in nonhomogeneous mixtures: Conditional statistics and implications for modeling, Combust. Flame 151 (2007) 120 - 141.

[13] A. Viggiano, Exploring the effect of fluid dynamics and kinetic mechanisms on n-heptane autoignition in transient jets, Combust. Flame 157 (2) (2010) 328-340.

[14] C.N. Markides, E. Mastorakos, An experimental study of hydrogen autoignition in a turbulent co-flow of heated air, Proc. Combust. Inst. 30 (1) (2005) 883-891.

[15] C.N. Markides, G. De Paola, E. Mastorakos, Measurements and simulations of mixing and autoignition of an n-heptane plume in a turbulent flow of heated air, Exp. Therm. Fluid Sci. 31 (5) (2007) 393-401.

[16] C.N. Markides, E. Mastorakos, Experimental investigation of the effects of turbulence and mixing on autoignition chemistry, Flow Turbul. Combust. 86 (3-4) (2011) 585-608.

[17] S.G. Kerkemeier, C.N. Markides, C.E. Frouzakis, K. Boulouchos, Direct numerical simulation of the autoignition of a hydrogen plume in a turbulent coflow of hot air, J. Fluid Mech. 720 (2013) 424-456.

[18] M.J. Papageorge, C. Arndt, F. Fuest, W. Meier, J.A. Sutton, High-speed mixture fraction and temperature imaging of pulsed, turbulent fuel jets auto-igniting in high-temperature, vitiated co-flows, Exp. Fluid. 55 (7).

[19] L. Vanquickenborne, A. van Tiggelen, The stabilization mechanism of lifted diffusion flames, Combust. Flame 10 (1) (1966) 59 - 69. 
[20] N. Peters, F. Williams, Lift off characteristics of turbulent jet diffusion flames, AIAA J. 21 (1983) 423-429.

[21] C. Muller, H. Breitbach, N. Peters, Partially premixed turbulent flame propagation in jet flames, Symp. (Int.) Combust. 25 (1) (1994) 1099 - 1106.

[22] L. Muñiz, M. Mungal, Instantaneous flame-stabilization velocities in lifted-jet diffusion flames, Combust. Flame 111 (1-2) (1997) 16-31.

[23] J. Buckmaster, Edge-flames, Prog. Energ. Combust. Sci. 28 (5) (2002) 435 - 475.

[24] J. Broadwell, J. Werner, M. Dahm, G. Mungal, Blowout of turbulent diffusion flames, Symp. (Int.) Combust. 20 (1) (1985) $303-310$.

[25] R.L. Gordon, A.R. Masri, S.B. Pope, G.M. Goldin, A numerical study of auto-ignition in turbulent lifted flames issuing into a vitiated co-flow, Combust. Theor. Model. 11 (3) (2007) 351-376.

[26] C. Yoo, R. Sankaran, J. Chen, Three-dimensional direct numerical simulation of a turbulent lifted hydrogen jet flame in heated coflow: flame stabilization and structure, J. Fluid Mech. 640 (2009) 453-481.

[27] T.F. Lu, C.S. Yoo, J.H. Chen, C.K. Law, Three-dimensional direct numerical simulation of a turbulent lifted hydrogen jet flame in heated coflow: a chemical explosive mode analysis, J. Fluid Mech. 652 (2010) 45-64.

[28] C. Yoo, E. Richardson, R. Sankaran, J. Chen, A DNS study on the stabilization mechanism of a turbulent lifted ethylene jet flame in highly-heated coflow, Proc. Combust. Inst. 33 (1) (2011) 1619-1627.

[29] Z. Luo, C. Yoo, E. Richardson, J. Chen, C. Law, T. Lu, Chemical explosive mode analysis for a turbulent lifted ethylene jet flame in highly-heated coflow, Combust. Flame 159 (1) (2012) $265-274$. 
[30] K. Lyons, K. Watson, Partially premixed combustion in lifted turbulent jets, Combust. Sci. Tech. 156 (1) (2000) 97-105.

[31] C. Lawn, Lifted flames on fuel jets in co-flowing air, Prog. Energ. Combust. Sci. 35 (1) (2009) 1-30.

[32] R. Venugopal, J. Abraham, A review of fundamental studies relevant to flame lift-off in diesel jets, SAE Paper 2007-01-0134,.

[33] S. Sreedhara, K.N. Lakshmisha, Autoignition in a non-premixed medium: DNS studies on the effects of three-dimensional turbulence, Proc. Combust. Inst. 29 (2) (2002) 2051 - 2059.

[34] S. Mukhopadhyay, J. Abraham, Influence of compositional stratification on autoignition in n-heptane/air mixtures, Combust. Flame 158 (6) (2011) 1064 - 1075.

[35] S. Mukhopadhyay, J. Abraham, Influence of heat release and turbulence on scalar dissipation rate in autoigniting n-heptane/air mixtures, Combust. Flame 159 (9) (2012) 2883 - 2895.

[36] S. Mukhopadhyay, J. Abraham, Influence of turbulence on autoignition in stratified mixtures under compression ignition engine conditions, Proc. Inst. Mech. Eng. 227 (5) (2012) 748-760.

[37] G. Borghesi, E. Mastorakos, R.S. Cant, Complex chemistry DNS of n-heptane spray autoignition at high pressure and intermediate temperature conditions, Combust. Flame 160 (7) (2013) $1254-1275$.

[38] A. Krisman, E.R. Hawkes, M. Talei, A. Bhagatwala, J.H. Chen, Polybrachial structures in dimethyl ether edge-flames at negative temperature coefficient conditions, Proc. Combust. Inst. 35 (1) (2015) 999-1006.

[39] S. Deng, P. Zhao, M.E. Mueller, C.K. Law, Autoignition-affected stabilization of laminar nonpremixed DME/air coflow flames, Combust. Flame 162 (9) (2015) 3437-3445.

[40] S. Deng, P. Zhao, M.E. Mueller, C.K. Law, Stabilization of laminar nonpremixed dme/air coflow flames at elevated temperatures and pressures, Combust. Flame 162 (12) (2015) 4471 4478. 
[41] A. Krisman, E.R. Hawkes, M. Talei, A. Bhagatwala, J.H. Chen, A direct numerical simulation of cool-flame affected autoignition in diesel engine-relevant conditions, Proc. Combust. Inst. (2016) submitted.

[42] Z. Zhao, M. Chaos, A. Kazakov, F. Dryer, Thermal decomposition reaction and a comprehensive kinetic model of dimethyl ether, Int. J. Chem. Kinet. 40 (1) (2008) 1-18.

[43] H. Ofner, D. Gill, C. Krotscheck, Dimethyl ether as fuel for CI engines - a new technology and its environmental potential, SAE Paper 1997-97-0873,.

[44] A. Bhagatwala, Z. Luo, H. Shen, J.A. Sutton, T. Lu, J. Chen, Numerical and experimental investigation of turbulent DME jet flames, Proc. Combust. Inst. 35 (2) (2015) 1157-1166.

[45] R. Sankaran, E.R. Hawkes, J.H. Chen, T. Lu, C.K. Law, Direct numerical simulations of turbulent lean premixed combustion, J. Phys. Conf. Ser. 46 (1) (2006) 38.

[46] C.S. Yoo, H.G. Im, Transient soot dynamics in turbulent nonpremixed ethyleneair counterflow flames, Proc. Combust. Inst. 31 (1) (2007) $701-708$.

[47] Y. Wang, C. Rutland, Direct numerical simulation of ignition in turbulent n-heptane liquid-fuel spray jets, Combust. Flame 149 (4) (2007) $353-365$.

[48] J. Chen, A. Choudhary, B. de Supinski, M. DeVries, E. Hawkes, S. Klasky, W. Liao, K. Ma, J. Mellor-Crummey, N. Podhorszki, R. Sankaran, S. Shende, C. Yoo, Terascale direct numerical simulations of turbulent combustion using S3D, Comp. Sci. Disc. 2 (1) (2009) 015001.

[49] C.S. Yoo, J.H. Chen, J.H. Frank, A numerical study of transient ignition and flame characteristics of diluted hydrogen versus heated air in counterflow, Combust. Flame 156 (1) (2009) 140 $-151$.

[50] E.R. Hawkes, R. Sankaran, J.H. Chen, Estimates of the three-dimensional flame surface density and every term in its transport equation from two-dimensional measurements, Proc. Combust. Inst. 33 (1) (2011) 1447 - 1454. 
[51] O. Chatakonda, E.R. Hawkes, A.J. Aspden, A.R. Kerstein, H. Kolla, J.H. Chen, On the fractal characteristics of low Damkohler number flames, Combust. Flame 160 (11) (2013) 2422 - 2433.

[52] M. Talei, E.R. Hawkes, Ignition in compositionally and thermally stratified n-heptane/air mixtures: A direct numerical simulation study, Proc. Combust. Inst. 35 (3) (2015) 3027 3035 .

[53] P. Domingo, L. Vervisch, Triple flames and partially premixed combustion in autoignition of non-premixed turbulent mixtures, Symp. (Int.) Combust. 26 (1) (1996) $233-240$.

[54] T. Echekki, J.H. Chen, Non-homogeneous hydrogen/air mixtures, Proc. Combust. Inst. 29 (2002) 2061-2068.

[55] Y. Ju, C.B. Reuter, S.H. Won, Numerical simulations of premixed cool flames of dimethyl ether/oxygen mixtures, Combust. Flame 162 (10) (2015) 3580 - 3588.

[56] M. Ihme, H. Pitsch, Prediction of extinction and reignition in nonpremixed turbulent flames using a flamelet/progress variable model: 1. A priori study and presumed PDF closure, Combust. Flame 155 (1-2) (2008) $70-89$.

[57] A. Coclite, G. Pascazio, P. De Palma, L. Cutrone, M. Ihme, An SMLD joint PDF model for turbulent non-premixed combustion using the flamelet progress-variable approach, Flow Turbul. Combust. 95 (1) (2015) 97-119.

[58] R. Gordon, A. Masri, S. Pope, G. Goldin, Transport budgets in turbulent lifted flames of methane autoigniting in a vitiated co-flow, Combust. Flame 151 (3) (2007) 495-511.

[59] J.H. Chen, E.R. Hawkes, R. Sankaran, S.D. Mason, H.G. Im, Direct numerical simulation of ignition front propagation in a constant volume with temperature inhomogeneities: I. Fundamental analysis and diagnostics, Combust. Flame 145 (12) (2006) 128-144.

[60] T. Echekki, J.H. Chen, Structure and propagation of methanol-air triple flames, Combust. Flame 114 (1998) $231-245$. 
[61] T. Echekki, J.H. Chen, Analysis of the contribution of curvature to premixed flame propagation, Combust. Flame 118 (1999) $308-311$.

[62] N. Chakraborty, E. Mastorakos, R.S. Cant, Effects of turbulence on spark ignition in inhomogeneous mixtures: A direct numerical simulation (DNS) study, Combust. Sci. Tech. 179 (1-2) (2007) 293-317.

[63] N. Chakraborty, H. Hesse, E. Mastorakos, Numerical investigation of edge flame propagation behavior in an igniting turbulent planar jet, Combust. Sci. Tech. 182 (11-12) (2010) 1747-1781.

[64] S. Karami, E.R. Hawkes, M. Talei, J.H. Chen, Mechanisms of flame stabilisation at low lifted height in a turbulent lifted slot-jet flame, J. Fluid Mech. 777 (2015) 633-689.

[65] S. Karami, M. Talei, E.R. Hawkes, J.H. Chen, Edge flame structure in a turbulent lifted flame: a direct numerical simulation study, Combust. Flame (In press).

[66] S. Karami, M. Talei, E.R. Hawkes, J.H. Chen, Local extinction and reignition mechanism in a turbulent lifted flame: a direct numerical simulation study, Proc. Combust. Inst. (Submitted).

[67] Y. Pei, E.R. Hawkes, S. Kook, G.M. Goldin, T. Lu, Modelling n-dodecane spray and combustion with the transported probability density function method, Combust. Flame 162 (5) (2015) $2006-2019$.

[68] L. Pickett, D. Siebers, C. Idicheria, Relationship between ignition processes and the lift-off length of diesel fuel jets, SAE Paper 2005-01-3843,. 